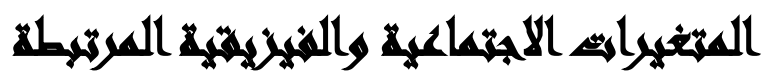

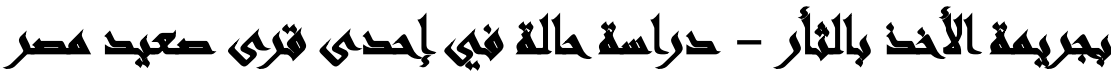

[?]

\author{
حاتم عبد المنعم أحمد|'- أحمد فخري هاني(')- أيمن عليو حسنين

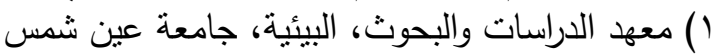

\section{ll}

تعتبر جريمة الأخذ بالثأر من الجرائم الخطيرة الني عانت منها المجتمعات البشرية وهي

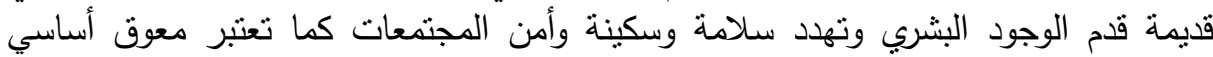

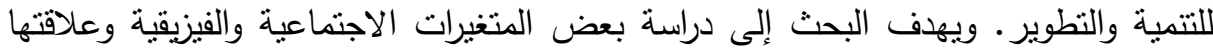

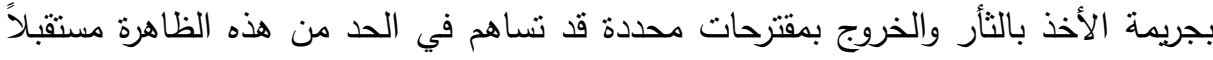

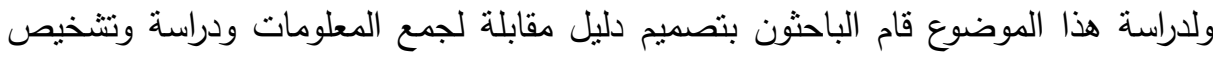

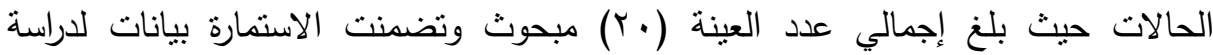

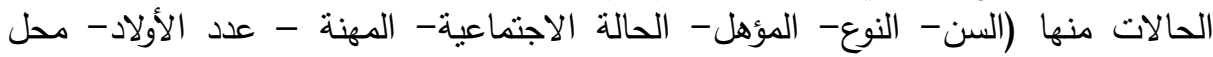

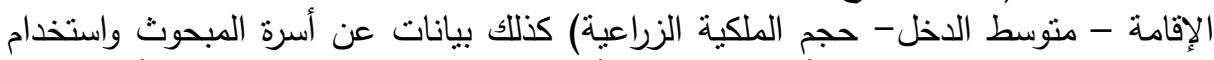

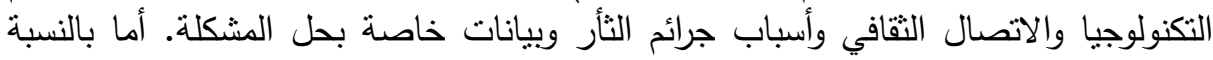

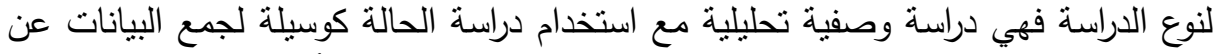

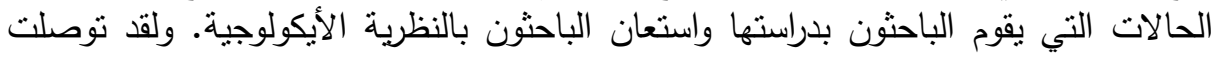

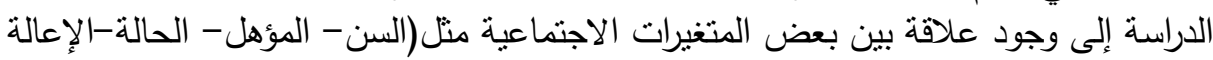

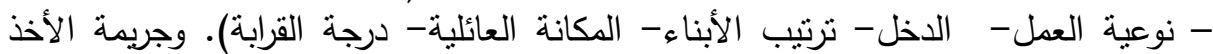

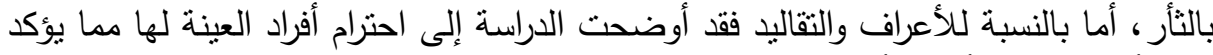

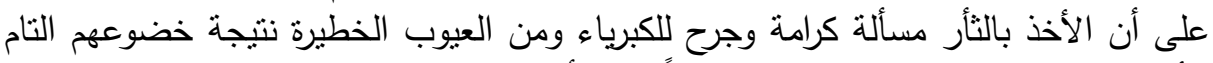

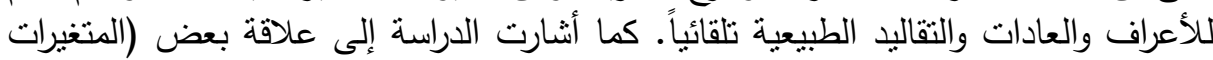

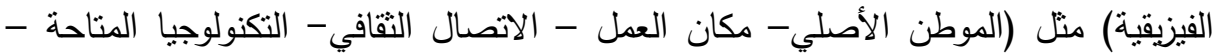

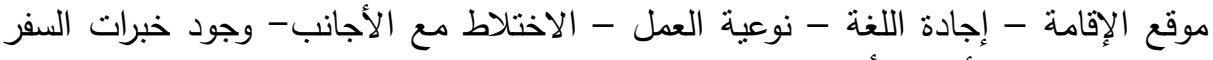

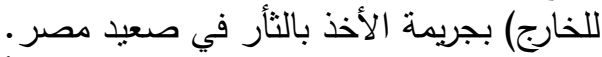

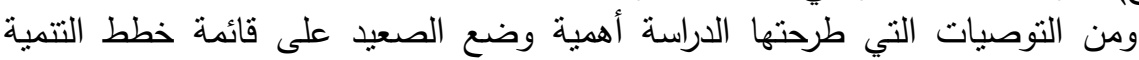

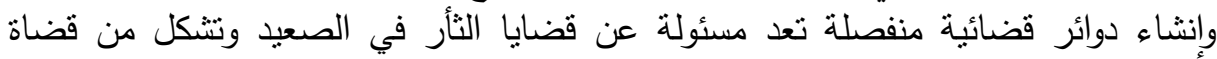
عرفيين وقضاة رسميين. 


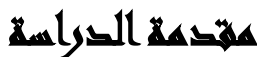

يعيش العالم حالياً مرحلة تدفق المعرفة وانفتاح المجمعات بعضها على بعض بسبب سهولة الاتصال وزيادة التداخل والنتابك بين مختلف الثعوب، وقد انعكست هذه المتغيرات على المجتمع المصري حيث شهدت مصر مجموعة من المتغيرات التي انعكست آثارها على جوانب كثيرة في الحياة الاجتماعية والتقافية والاقتصادية نتج عنها انتتار الهجرة من الريف إلى المدينة ومن الريف إلى خارج البلاد وانتشار التعليم وتعدد مؤسساته وانتشار وسائل الاتصال والإعلام ودخول العديد من الأدوات الحديثة والأجهزة التكنولوجية والكمبيوتز وما يحتويه من شبكات الإنترنت ومواقع التواصل الاجنماعي. ورغم تعرض المجتمع المصري لهذه المتغيرات وتأثره بها إلا أن المجتمع الريفي مازال محتفظاً بسماته التقليدية وبخاصة في صعيد مصر حيث تظل الثقافة التقليدية هي النقافة

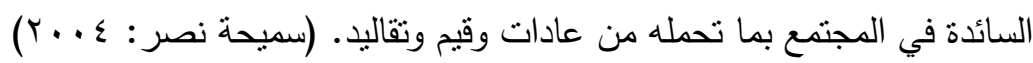
والثأر كأحد أهم هذه العادات والتقاليد في صعيد مصر التي تتنتر وبشكل ملحوظ مهددة

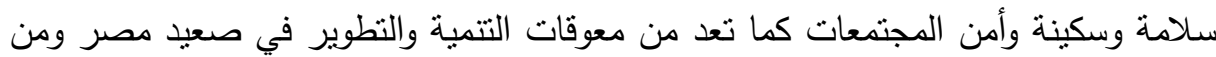
أعقد الجرائم التي تؤثر في حياة المجتمع كما تعد من أسوأ العادات والثقاليد الاجتماعية الموروثة التي تعيق عملية التتمية وتؤدي إلى سفك دماء الكثير من الأبرياء نتيجة قيام العديد من الصراعات والنزاعات القبلية والعائلية خاصة في مجتمع الصعيد الذي لتئي يتميز بالعصبية

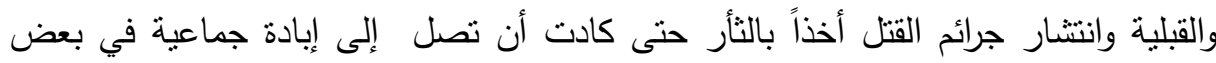

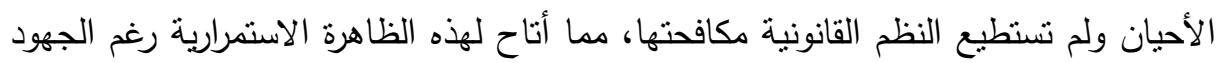

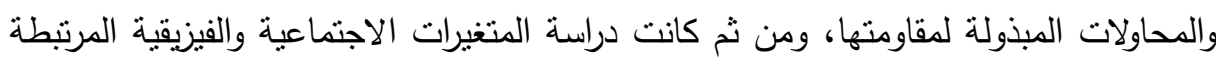
بجريمة الأخذ بالثأر في صعيد مصر من الموضوعات الهامة والمثيرة في نفس الوقت

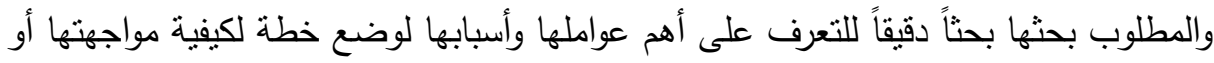




\section{مهرحلة التراسما}

إن مشكلة الثأر مشكلة بالغة الأهمية رغم ما يبذل من جهود أمنية وثقافية للحد منها، وهي مشكلة تؤثر بثدة في مجتمعنا المصري بصفة عامة وفي مجتمع الصعيد بصفة خاصة، الصنا، الأمر الذي يؤكد على أهمية بل وضرورة دراسة تلك الظاهرة (الأخذ بالثأر) من الناحية البيئية

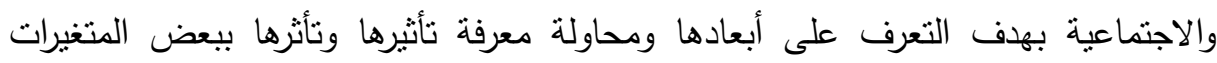
الاجتماعية والفيزيقية، وبالتالي محاولة التخفيف من حدتها وتداعياتها على الأفراد. إن مراجعة الإحصاءات العامة التي تصدرها مديريات الأمن التابعة لوزارة الداخلية في

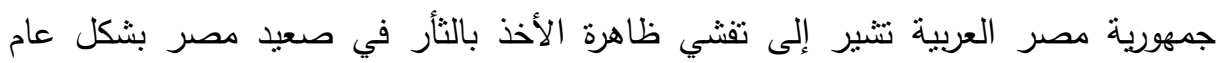

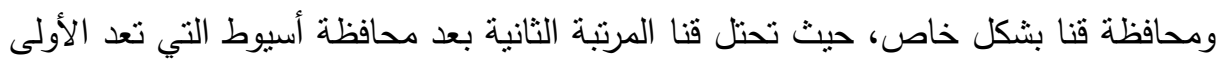

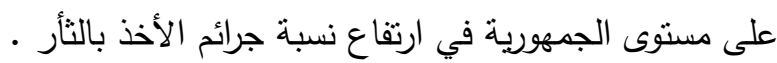
ومن خلال الدراسة الاسنطلاعية التي قام بها الباحثون والدراسات التي أنتح للباحثون الاطلاع عليها حول ظاهرة جريمة الأخذ بالثأر وما يرتبط بها من متغيرات اجتماعية وبيئية

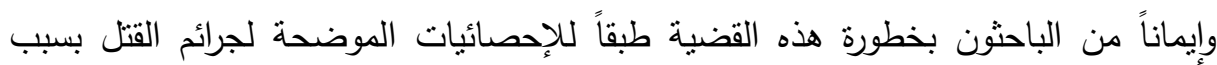

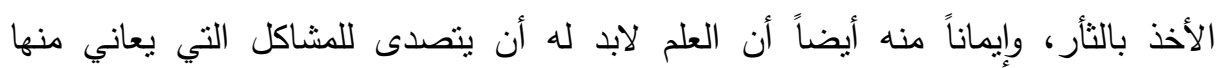

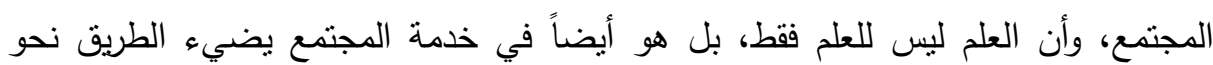
التقدم والرقي. لذلك اتجه الباحث إلى دراسة ظاهرة الأخذ بالثأر كمشكلة اجتماعية وبيئية

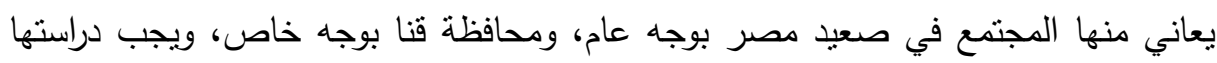
دراسة علمية وافية. 
جدول رقم(1): بيان حوادث الثأر في محافظة قنا موزعة على المراكز والأقسام خلال عامي

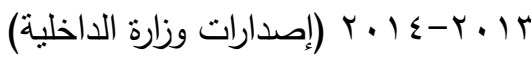

\begin{tabular}{|c|c|c|}
\hline عدد حوادث الثًار & المركز والآقَسام & e \\
\hline 11 & مركز آبو نشت & 1 \\
\hline $1 \pi$ & مركز قوص & $r$ \\
\hline 11 & نجع حمادي & $r$ \\
\hline 9 & مركز ومدينة قنا & $\varepsilon$ \\
\hline$\Lambda$ & دشنا & 0 \\
\hline $\mathrm{V}$ & مركز نقادة & 7 \\
\hline$\varepsilon$ & فرشوط & $\mathrm{V}$ \\
\hline r & ققط & $\Lambda$ \\
\hline $\bar{r}$ & الوقف & 9 \\
\hline$T$ & دندرة دن & 1. \\
\hline
\end{tabular}

بالنظر إلى بيانات الجدول السابق الذي يوضح حوادث الثأر في محافظة قنا خلال

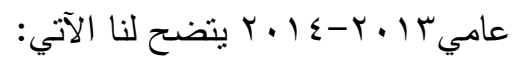

• تشنير بيانات الجدول السابق إلى أن حوادث الثأر تتشمل معظم مراكز المحافظة وأن مركز دندرة هو أقل تلك المراكز انتشاراً لمثل هذه الجرائم. • أن مركز نقادة الذي اختار الباحث عينته من بعض قرى هذا المركز أن حوادث الثأر لثراث

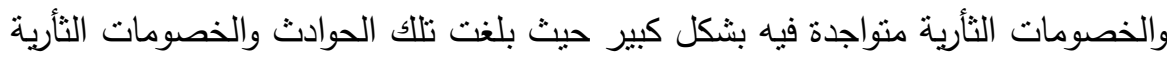

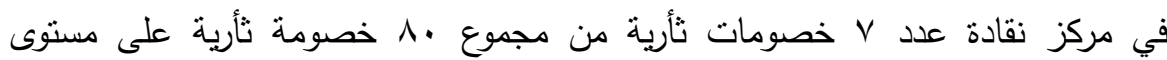
محافظة قنا تم انتهاء 0 خصومات ثأرية من خلال لجان المصالحات وذلك بنسبة مئوية

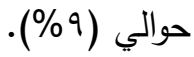

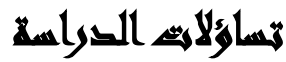

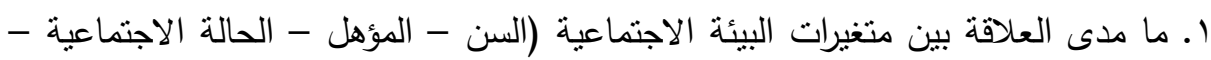

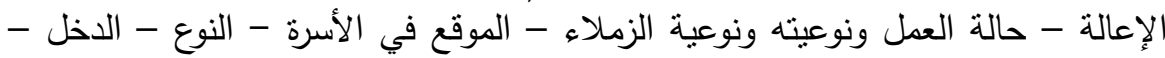
العادات والتقاليد- الأعراف والقيم - التنشئة الاجتماعية - ترتيب الأبناء - المكانة الأنة العائلية

- درجة القرابة) وجريمة الأخذ بالثأر في صعيد مصر؟ الأبن 
r. ما مدى العلاقة بين متغيرات البيئة الفيزيقية (الموطن الأصلي- مكان العمل - الاتصال

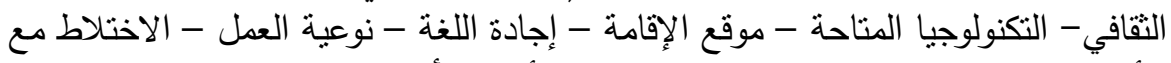

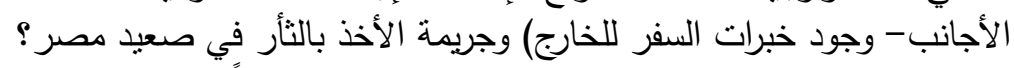

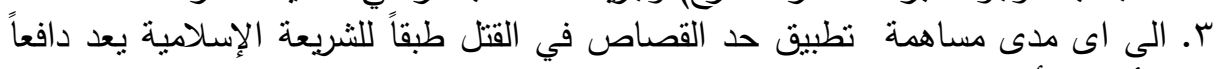

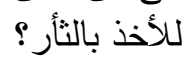

ع. ما هو الدور الذي تلعبه الرأة الصعيدية للتحريض على الأخذ بالثأر؟ وما هي الوسائل التي تستخدمها؟ التوري ه. ما أمكانية وضع رؤية علمية حول كيفية المواجهة وما هي وسائل وأدوات تخفيف نلك المواجهة؟

\section{أهساهث التراسما}

ا ـ التعرف على أهم المتغيرات الاجتماعية المرتبطة بجريمة الأخذ بالثأر في صعيد مصر .

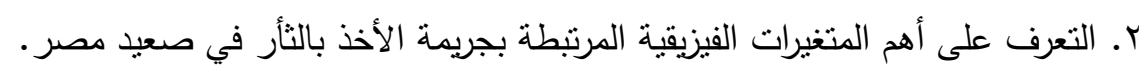

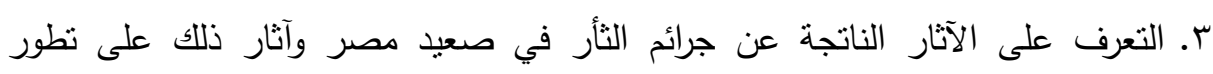

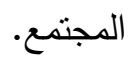

ع. الخروج بمقترحات محددة قد تساهم في الحد من هذه الظاهرة مستقبلاً.

\section{أهمية التوراسم}

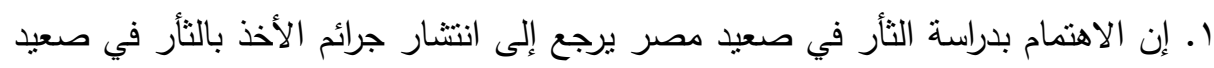

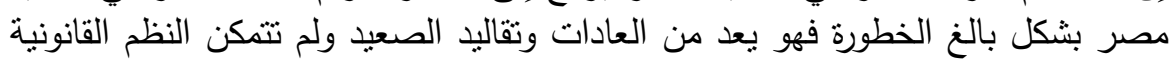

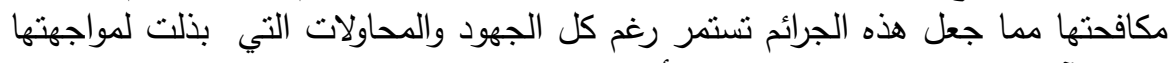

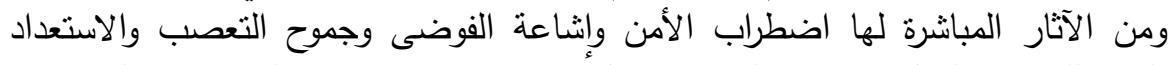

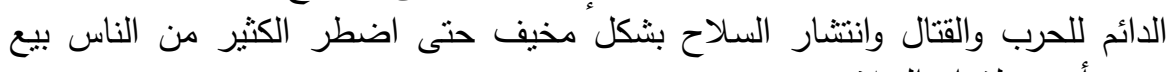
ورهن أرضده لثراء السلاح.

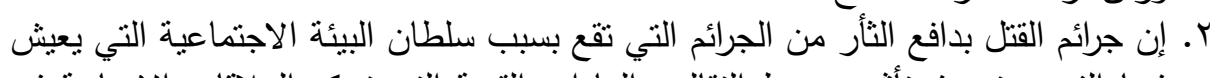

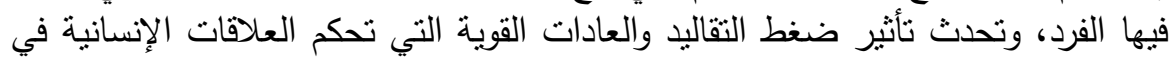

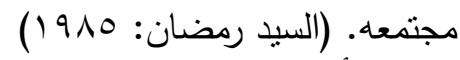

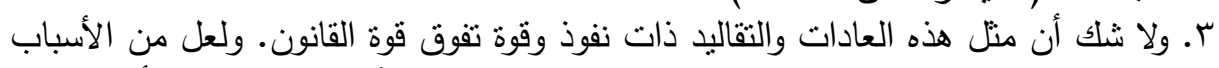

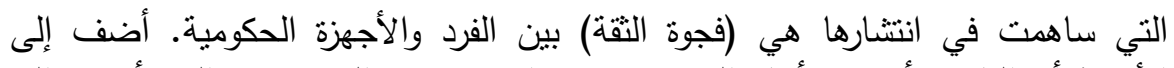

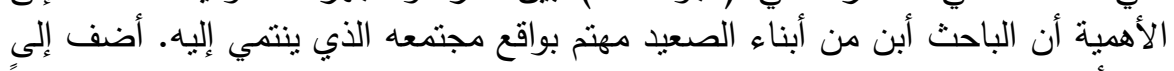

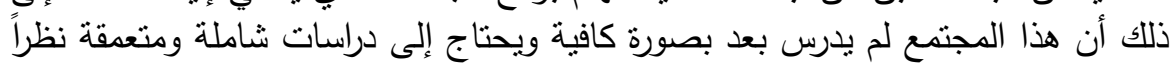

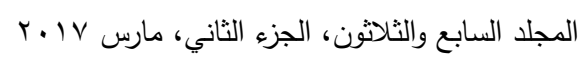


إلى تحول القتل إلى إبادة جماعية في أغلب الأحيان مما يهدد الأمن والاستقرار اللازمني لحدوث التنمية.

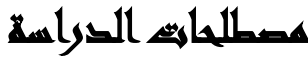

ا. مفهوم المتغيرات الاجتماعية: يقصد بها المتغيرات البيئية الاجتماعية وهي كل المحيط الاجتماعي الذي يعيش فيه الإنسان وهي مجال احتياجاته وتطلعاته وتتقسم إلى جزئين أساسبين: • جزء يرجع للماضي البعيد ويشمل العادات والتقاليد والأعراف والقيم. • الجزء الثاني يرجع للحاضر ويشمل النظم النتريعية والسياسية والثقافية وغيرها من النظم

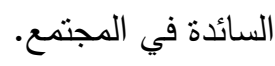

والمتغيرات الاجتماعية هي جميع مظاهر البيئة المرتبطة بالإنسان وأنشطته وهي بالتالي تتكون من أنشاص وجماعات ومجتمعات متفاعلة وينطوي على التوقعات الاجتماعية ذات الطبيعة الفردية الأمر الذي يجعل لكل عضو في المجتمع بيئته الخاصة به (حانم عبد المنعم

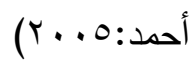

والمتغيرات المجتمعية المرتبطة بجريمة الأخذ بالثأر تتقسم إلى ( السن - المؤهل -

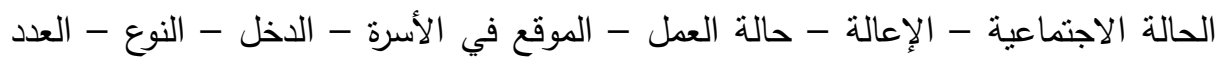
والتقاليد - الأعراف والقيم - التتشئة الاجتماعية - ترتيب الأبناء - الدكانة العائلية - درجة الإنة القرابة). المتغيرات الفيزيقية: المتغيرات الفيزيقية: كما عرفها حاتم عبد المنعم هي جميع مظاهر البيئة التي لا تكون من خلق الإنسان أو نتيجة للنشاط الإنساني أي ليس للإنسان دخل بها عان على الإطلاق ويتضمن

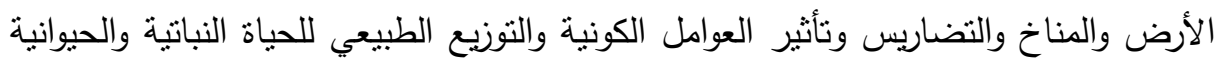

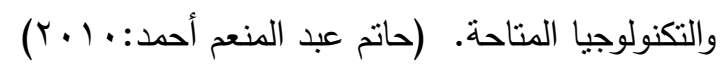


ونعني بها في هذا البحث (الموطن الأصلي (الريف والحضر) - مكان العمل ( قطاع

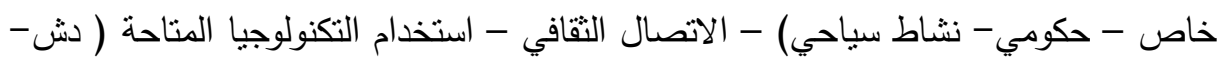

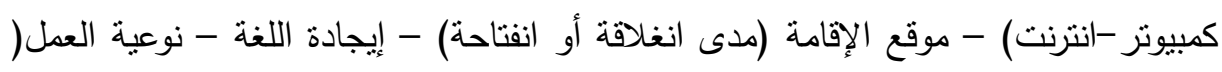

$$
\text { زراعي - تجاري) - الاختلاط مع الأجانب - وجود خبرات السفر للخارج). }
$$

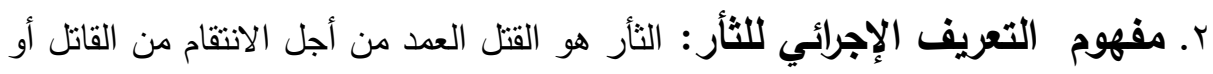
أسرته أو عائلته لأنها نسببت في قتل أحد أفراد عائلة أخرى وليس شرط أن يكون الضحية هو الجاني الأصلي، وهي عملية جماعية ومجتمعية منظمة ومخططة ومحدد دور كل فرد التها فيها.

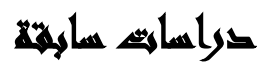

ا. دراسة منى محرم عبد المجيذ( . . . r) اهتمت هذه الدراسة بدراسة البناء النفسي

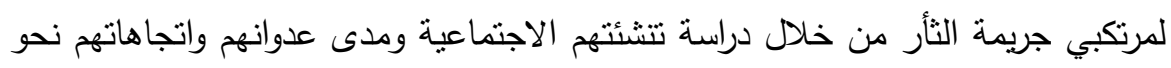
الجريمة كذلك معرفة ما إذا كانت حالة طارئة ناتجة لضغوط الأسرة والبيئة أو أن هناك دأك دوافع أخرى وانتهت إلى وجود فروق دالة إحصائياً بين مجموعات الدراسة الثلاث القتلة لداتة

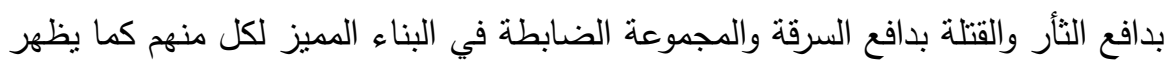

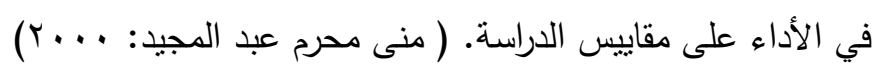

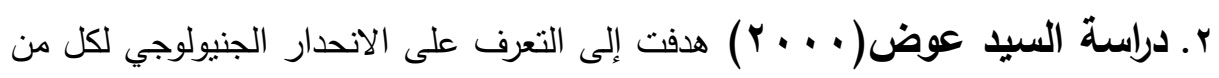

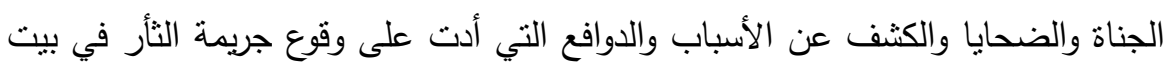
علام وتوصلت الدراسة إلى أن أغلب الجناة من الثباب وأكثر الضحايا كانوا والاًاً

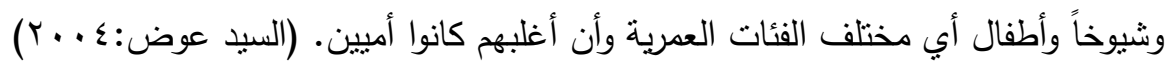

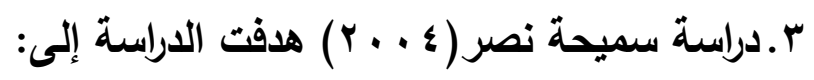
• السعي إلى النظر في ثقافة الثأر في الصعيد من حيث ثناتها واستمرارها أو تغيرها.

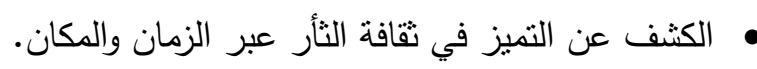
• الحاجة الماسة إلى تقهم استمرار ثقافة الثأر والكثف عند عن آليات هذا الاستمرار . 
وخلصت الدراسة عن وجود تغيرات في ثقافة الثأر في الصعيد وخاصة في قوانين الثأر ،

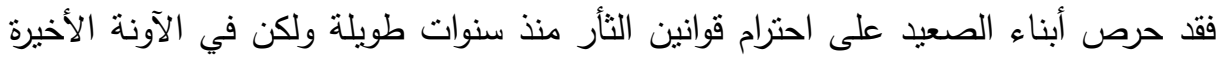

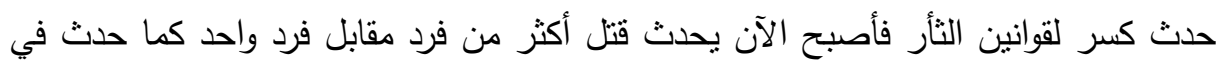

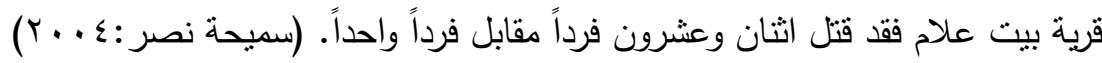

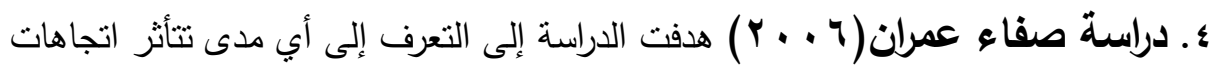

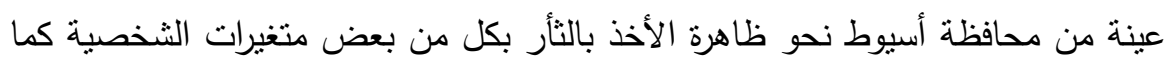
يقيسها استبيان ايزنك للثخصية ومقياس التعصب ومقياس القلق لتايلور (صفاء

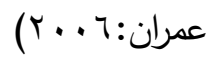

وخلصت الدراسة إلى وجود فروق في سمات الشخصية بين الأكثر تمسكاً والأقل تمسكاً بالاتجاه نحو ظاهرة الأخذ بالثأر في بعد الجريمة والعصابية والذهانية والدرجة الكلية للاستخبار إيزنك للشخصية للمقياس في اتجاه الأكثر تماسكاً بظاهرة الأخذ بالثأر.

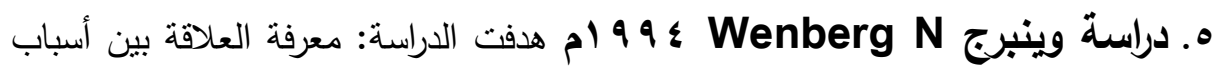

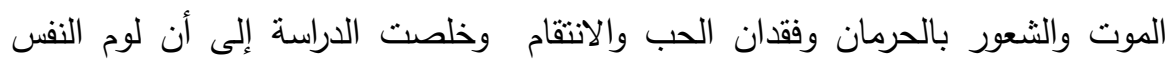
والرغبة في اتهام النفس والانتقام كانت ممثلة بصورة اكبر في حالات الوفاء غير طبيعية. (Poussaint, Alvin F: 1984)

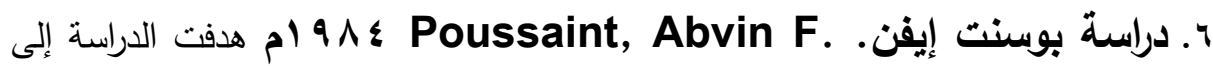
معرفة مشاعر الحزن الناتج عن قتل فرد من أفراد العائلة، ورد الفعل لدى بعض أفراد العائلات التي قتل أحد أعضائها وخلصت الدراسة إلى أن القتيل يكون لهم تفاعلات

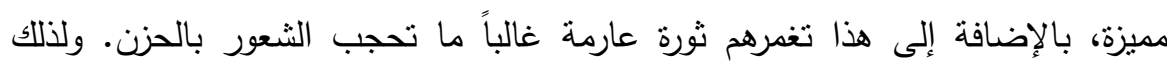

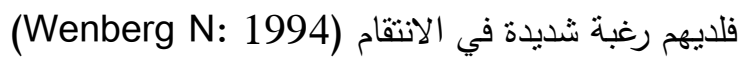




\section{الإسار النظظيه اللدراسة}

النظرية الأيكولوجية: كلمة Ecology مشنقة من الأصل الأغريقي Ekos ومعناها بيت

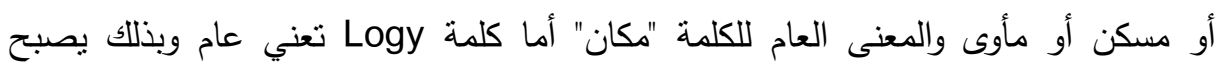

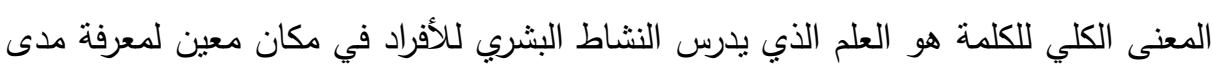
التفاعل بين الإنسان والمكان. (Fred, W. Riggs, 1961)

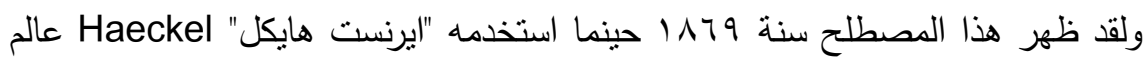

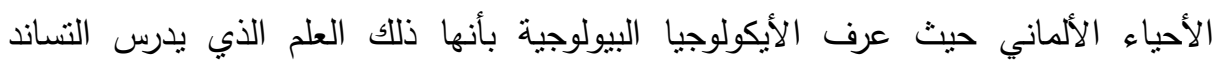
المنبادل بين النباتات والحيوانات التي تعيش معاً في منطقة طبيعية. (السيد الحسيني:

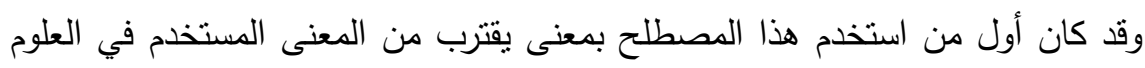

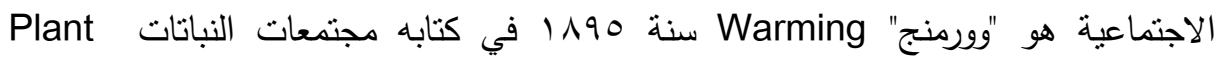
Communities

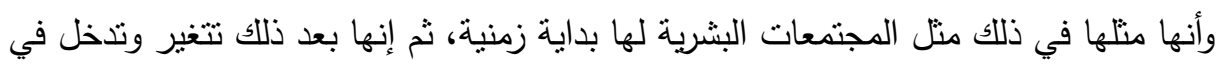

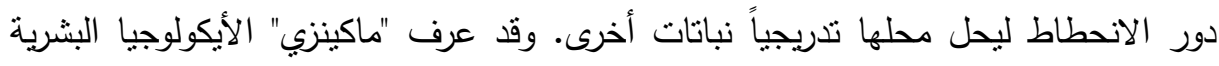

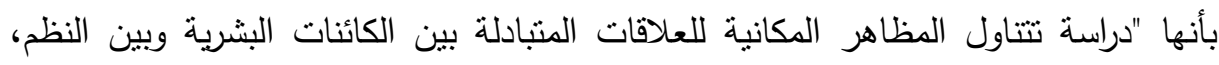

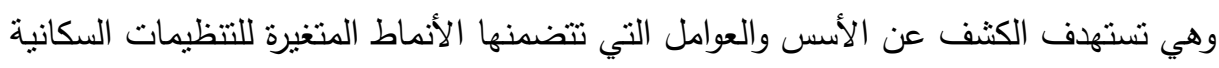
والنظم التي تتثأ عن التفاعل بين الناس في ظل ثقافة مستمرة في تنغيراتها. ( محمد عارف:

وقد عرف الدكتور أحمد رأفت الأيكولوجيا البشرية بأنها "عملية توزيع مختلف الجماعات

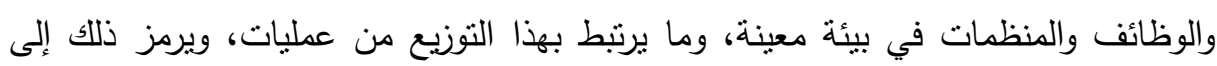

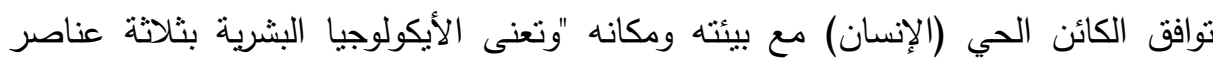

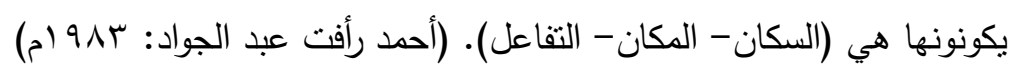

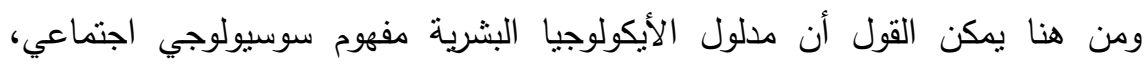

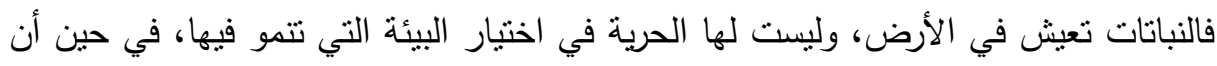

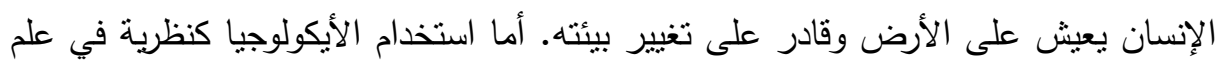

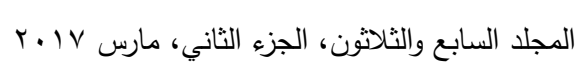


الاجتماع فقد تم في أمريكا على يد "بارك" وأتباعه في جامعة شيكاغو، فقد تصور "بارك"

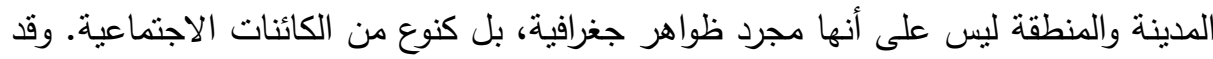

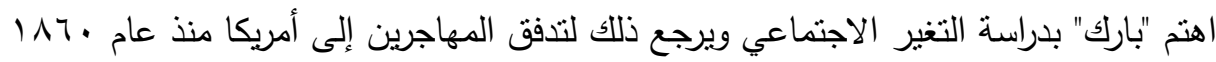

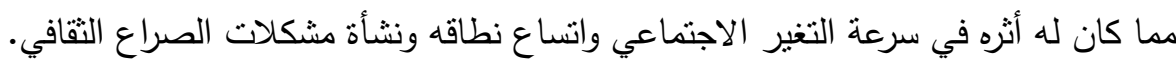

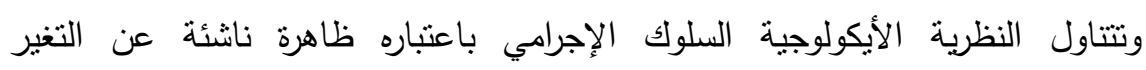

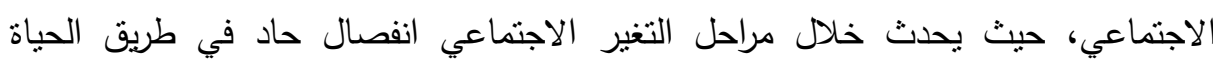
المادية والاجتماعية، ويحدث هذا الانفصال بصورة غير منساوية في المكان، ولذا فإنه يؤثز

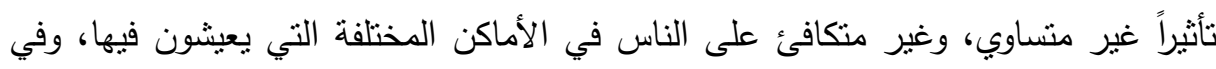
الأزمنة المختلفة فهي تتناول العلاقة بين الناس والبيئة المكانية وردود الأفعال الناشئة من فئن المؤثرات والضغوط البيئية، وهذه العلاقة ليست ثابتة بل هي في تغير مستمر ، وتتشنأ عنها

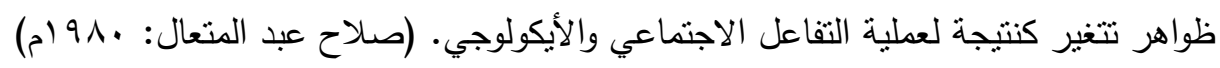

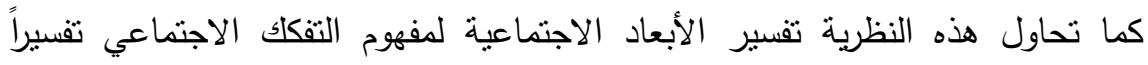

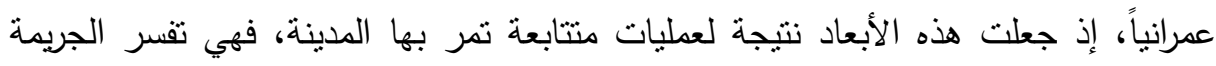

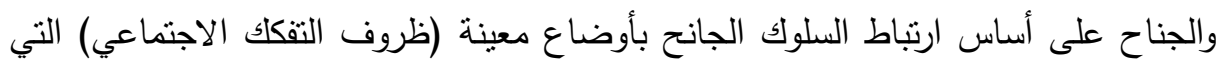
تتشأ نتيجة عمليات نمو المدن، ولا نتظر هذه النظرية إلى عامل انخفاض مستوى المعيشة

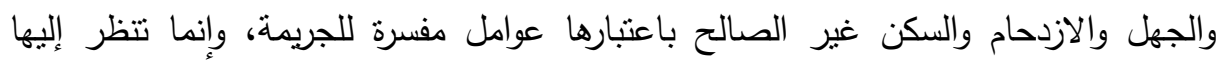
باعتبارها أعراضاً لنظام انحلالي Degenerative أي أن المناطق الإجرامية يرجع ظهورها

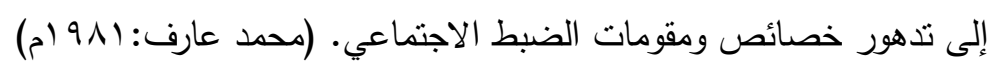

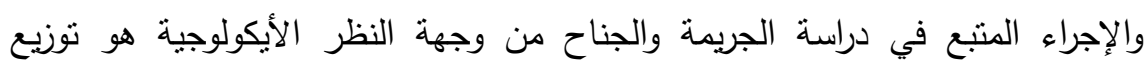

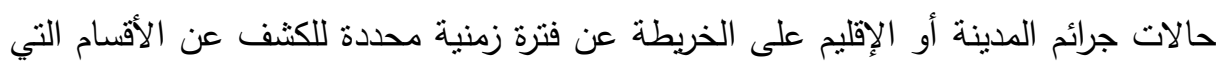
حدثت فيها تركز للحالات، والمناطق التي يندر حدوثها فيها، حيث يتضح التفاوت بين معدل

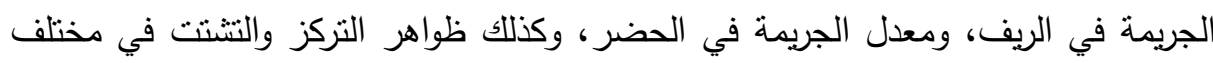

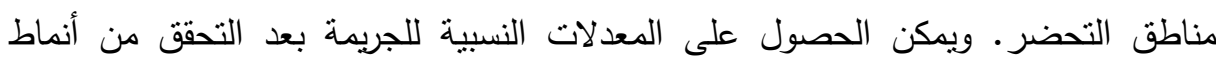

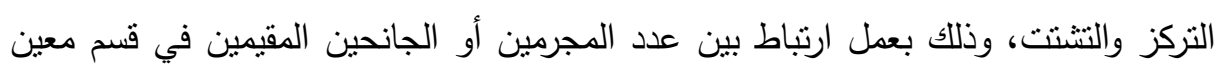

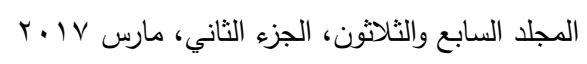


وعدد سكان هذا القسم، ويمكن أيضاً الربط بين معدلات الجريمة والجناح في الأحياء وبين

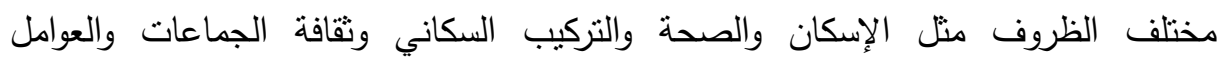

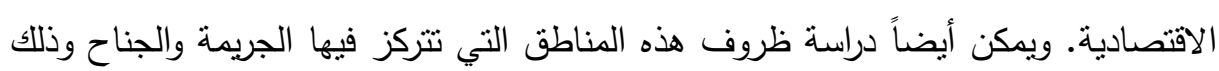

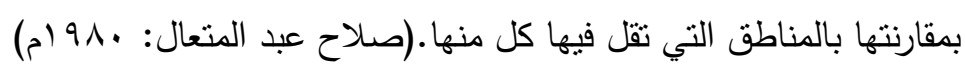

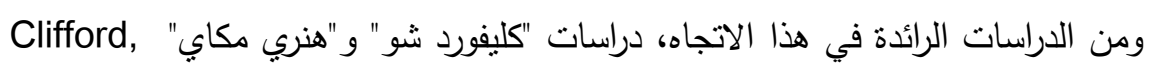
R. Show \& H., D. Mckay

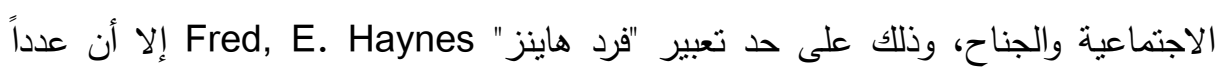

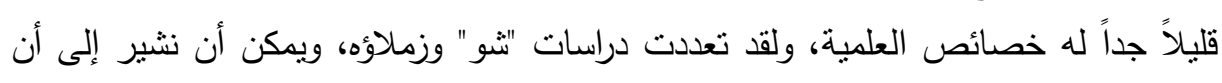

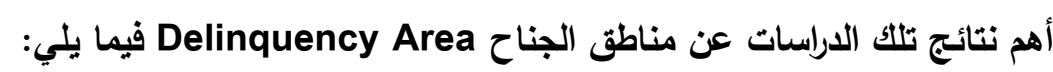
1. هناك ارتباط قوي بين المناطق الإجرامية من ناحية وإجرام الأحداث من ناحية أخرى.

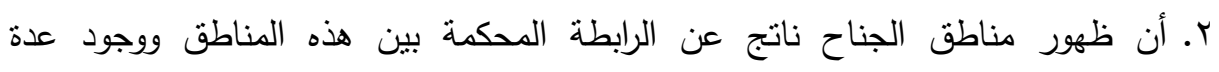

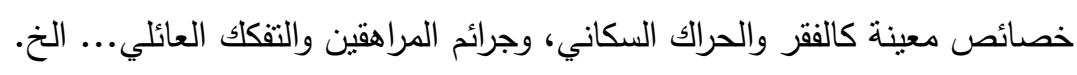

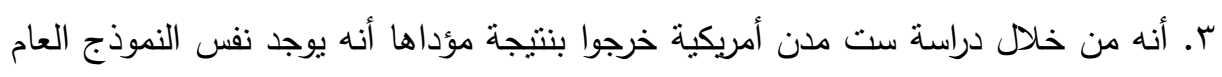

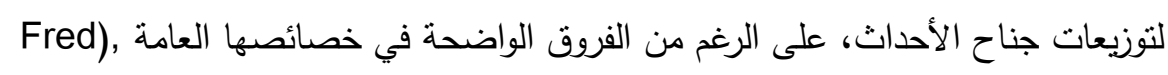

(H, Haynes: 1935

ع. تختلف معدلات الجناح اختلافاً كبيراً من منطقة إلى أخرى.

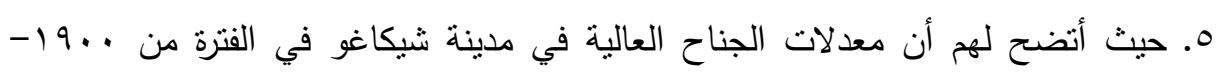

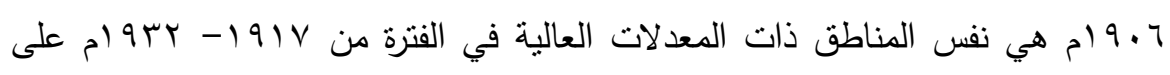
الرغم من أن تكوين الجماعات السلالية قد تغير إلى حد كبير . فمناطق الجناح في المدينة

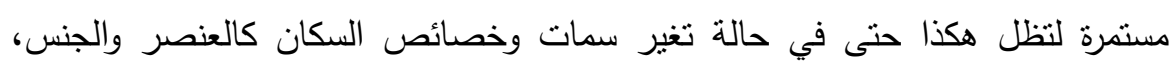

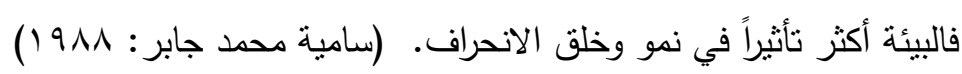

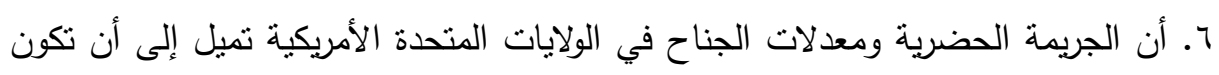

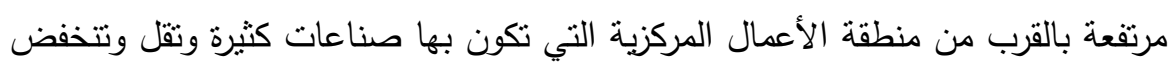
كلما بعدنا عن المركز، فحركة الجريمة يكثر حجمها في وسط المدينة، حيث التفكل 
الأسري وكثافة السكان العالية، والجيرة المتغيرة الناتجة عن الهجرة منها وإليها. John)

)Lewis and Others: 1969 V. وعن أثز الأسرة المفككة على الجناح، ومن خلال مقارنة جماعة من المنحرفين بجماعة

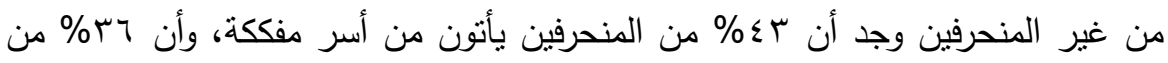

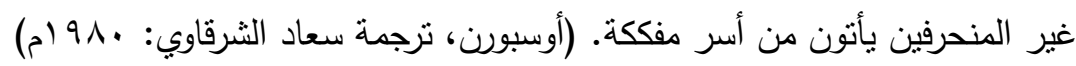

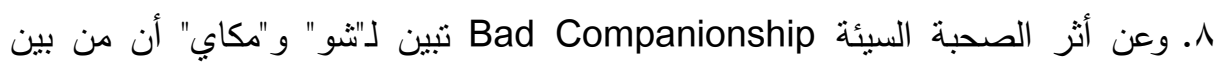

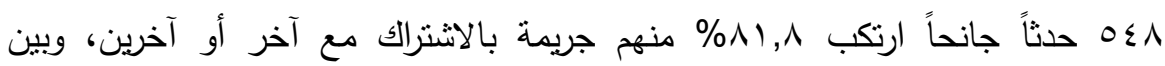

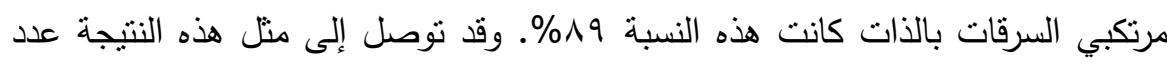
آخر من العلماء منل "جلوك" و "هيلي" و "برولر ".

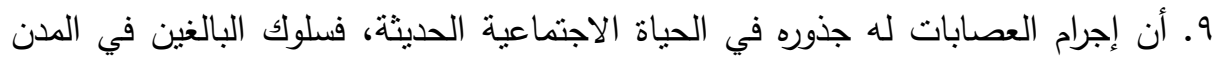
الكبرى من شأنه تغذية إجرام الأحداث الذين يختلطون بهم، فالقيم المتصارعة في الحياة الحديثة تصيب الطفل الناشئ بالتخبط وتتجعه على البحث عن حياة مثيرة يسنطيع أن يحقق فيها مركزاً يرضيه في مواجهة أقرانه. (أحمد عوض بلال: 910 (1910)

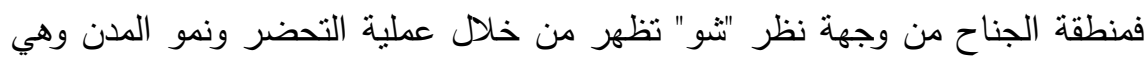
تتميز بأن معدلات الجريمة بها مرتفعة للغاية، وبتهالك مبانيها، وسوء الحهاء الحالة الاقتصادية والاكتظاظ السكاني، وانخفاض مستوى المعيثة، وعدم التجانس القومي والعنصري للسكان ومعدلات مرتفعة للحركة السكانية، والتغيب والهروب من المدارس، وارتفاع نسبة وفيات

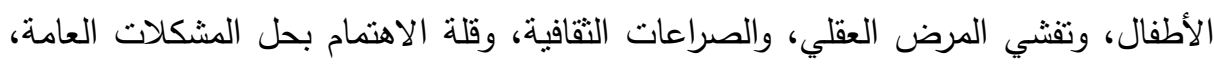
وتدهور خصائص ومقومات الضبط الاجتماعي، وهي باختصار مناطق تتسم بالتفكلى الاجتماعي.

وهنالك دراسات كثيرة وصلت إلى نتائج مماثلة منها دراسة "ثزاشر" Thrasher عام

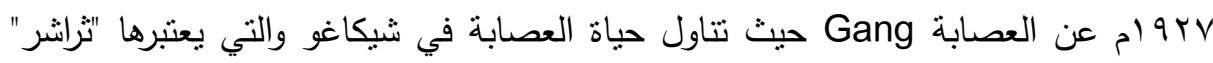

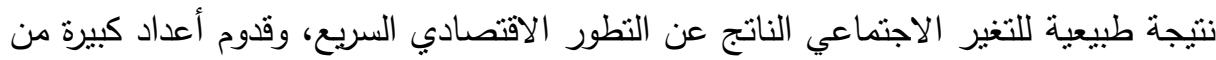

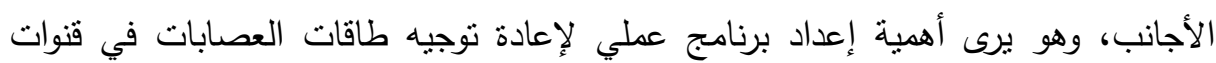


صحية. ومن أهم الدراسات التي استخدمت المدخل الأيكولوجي واستتدت على دراسات "شو" و "مكاي" في دراسة الجريمة والانحراف، دراسة "برنارد لاندر" Bernard Lander في دراسته لأنكات نحو فهم جناح الأحداث: Towards Understanding of Juvenile Delinquency، حيث قام برنارد لاندر بتحليل عينة من الجانحين المقيمين في بالتمور Baltimore بلغت

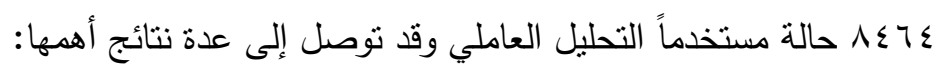
ا ـ أن عمليات نمو المدن لا تمدنا بالأساس التفسيري للاختلافات الكبيرة في معدلات التهل الجناح. r. أنه لا يوجد ارتباط بين السكن والجناح، ولا بين العنصر والجناح.

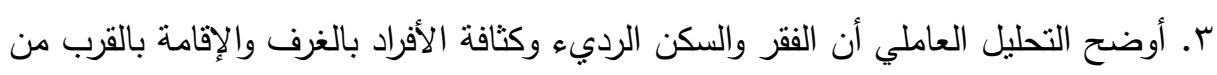

$$
\text { مركز المدينة ذات علاقات بسيطة. }
$$

ع. أن العوامل الوحيدة ذات الارتباط الفعلي بالجناح هي ملكية السكن وكثافة سكان الزنوج.

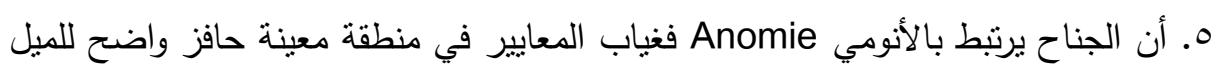

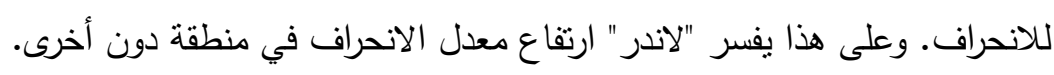

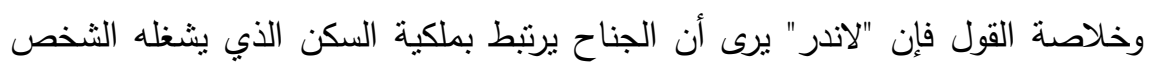

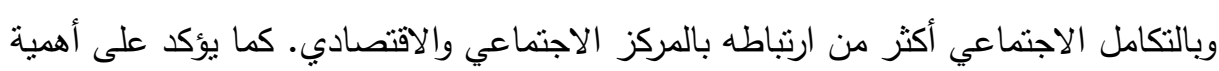

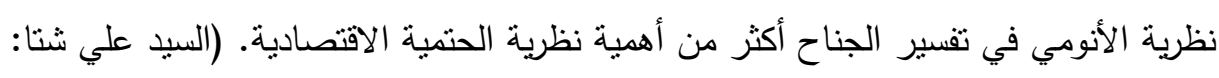

وفي دراسة أجريت عام • 97 ام في منطقة ملوكي Milwukee بأمريكا وجد أن الجريمة

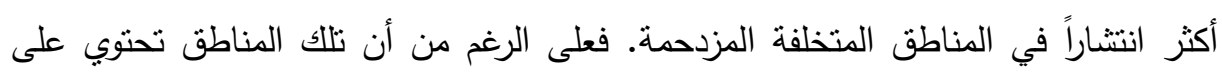

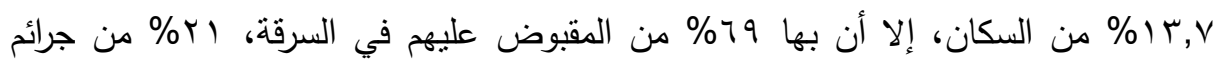

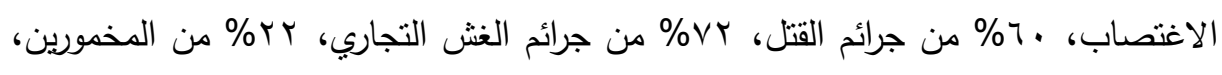
\% مr

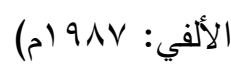

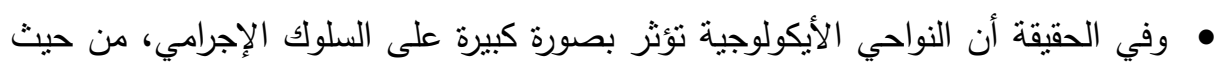

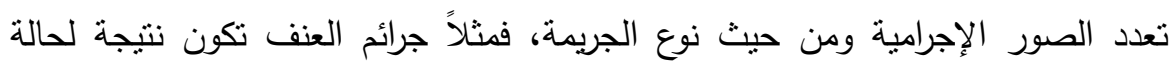
انفعالية مؤقتة فيما يؤكد وجودها أو حدوثها في نفس منطقة الإقامة عكس جرائم الممتلكات

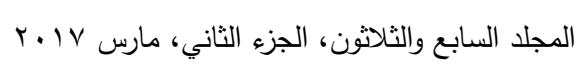


التي يكون لها نوع من التخطيط، فهي تبعد عن مقر إقامة المجرم، أو بعيداً عن البيئة

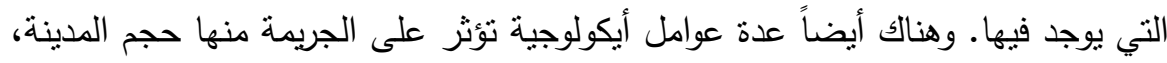

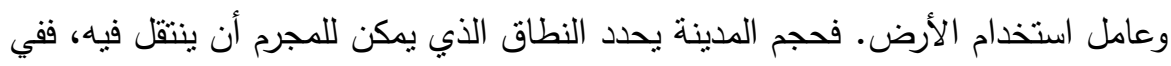
المدينة الكبيرة تتعدد المناطق التي يزاول فيها المجرم نشاطه، في حين أن المدينة الصغيرة

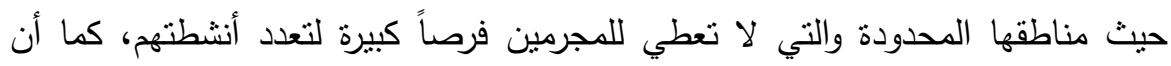

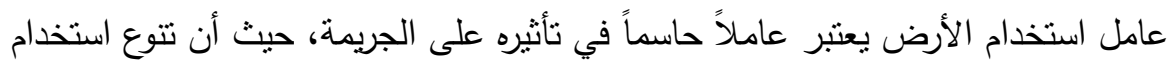
الأرض يؤدي بالتالي إلى أن نتغير نوع الجريمة، فنمو النشاط التجاري في منطقة معينة

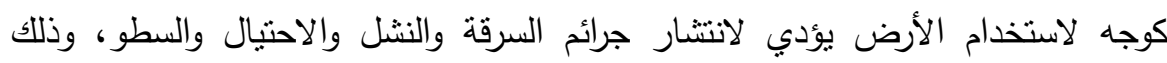

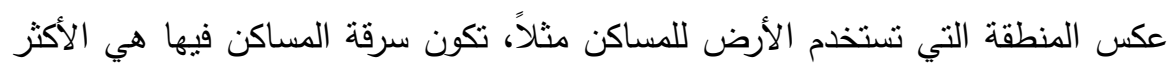

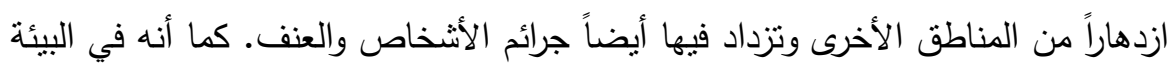

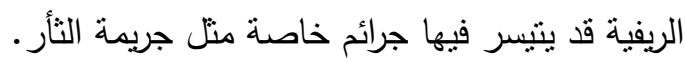

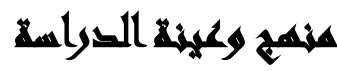

تعد هذه الدراسة من الدراسات الوصفية التحليلية حيث تقوم بوصف الخصائص العامة لمجتمع الدراسة ولجأت الدراسة إلى منهج دراسة الحالة للتعرف بشكل أكثر تفصيلاً وتعمقاً بهدف لفت النظر إلى أبعادها المختلفة والآثار المترتبة عليها وقام الباحث بتطبيق دراسته في بعض قرى محافظة قنا على عينة قوامها عشرون مفردة.

\section{مجالايه التراسلا}

المجال الجغرافي: شملت الدراسة قرية دنفيق وقرية اسمنت بمحافظة قنا. المجال البشري: اختار الباحثون (•r) مفحوص من الفئات المختلفة في (النوع- العمر الحالة الاجتماعية-التعليم- الوظيفة) من منطقة الدراسة. المجال الزمني: أما بالنسبة للفترة الزمنية التي استغرقتها الدراسة الميدانية فقد بلغت عشر الثر

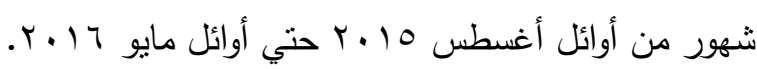


أدوات الدراسة: تم إعداد عمل دليل المقابلة وفق استمارة مقابلة مفتوحة نركزت الأسئلة حول (السن - النوع - المؤهل - الحالة الاجتماعية - المهنة - عدد الأولاد - متوسط الدخل - حجم الملكية الزراعية - بيانات عن أسرة المبحوث واستخدام التكنولوجيا - والاتصال الثقافي - أسباب جرائم الثأر - بيانات خاصة بحل المشكلة ..... الخ)

\section{نمأئج الصراسة}

نظرا لأن صيغة الدراسة حول عدد قليل من الحالات (دراسة حالة متعمقة) مما جعل الباحثون يعرضون نتائجهم وفق وصف الحالات.

\section{أهم النتائج الاجتماعية المرتبطة بجريمة الأخذ بالثأر كما أوضحت دراسة}

ا ـ بالنسبة لمتغير السن: من خلال دراسة دليل الحالة المتعمق تبين للباحث أن كبار السن يعدوا من أهم المحرضين على جرائم الثأر في قرية البحث وأن السيدات الكبار بلعبن دوراً

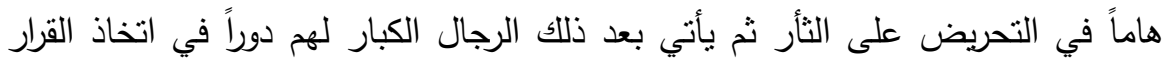
والتخطيط وأن صغار السن من الثباب ينزك لهم دور التنفيذ. r. بالنسبة لمتغير المؤهل: تبين للباحث أن هناك تقدير لدور التعليم في التتوير وأن الأفراد

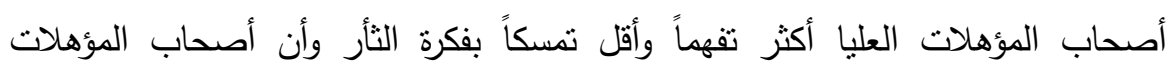
المتوسطة ودون المتوسطة أكثر تمسكاً بعادات وثقاليد الثأر.

r. بالنسبة لمتغير النوع: من خلال دراسة الحالة تبين أن الرجال وخاصة الكبار أكثر تمسكاً

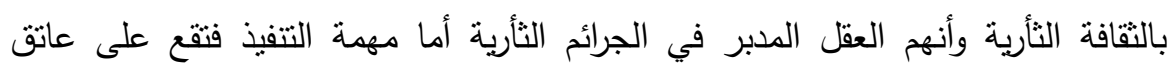

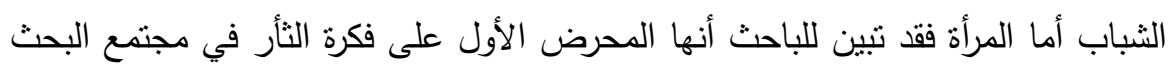

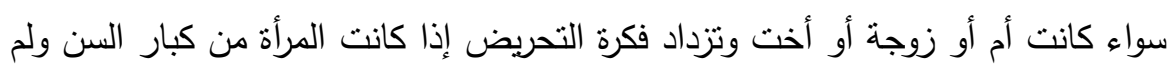

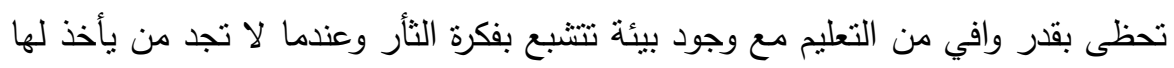

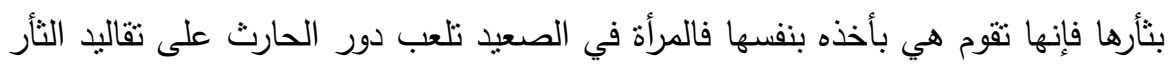

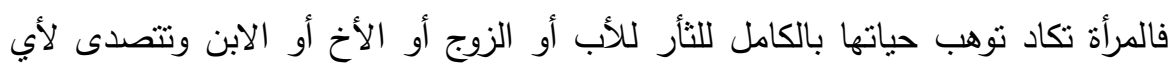
محاولة من أفراد أسرتها للتهرب من أخذ الثأر.

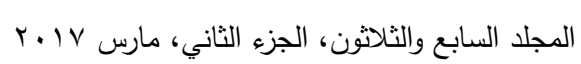


ء. بالنسبة لمتغير الاخل: تبين للباحث من خلال التعمق في دراسة الحالة إلى عدم وجود اختلاف في مسألة الثأر بين العائلات في الصعيد غير أن العائلات الغنية قد تكون أسرع فئه

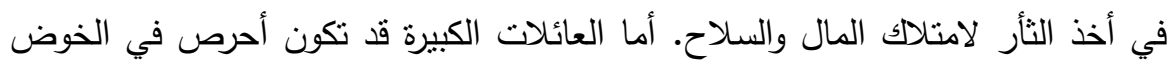
في مسألة الثأر وقد نبين للباحث إصرار العائلات الفقيرة على أخذ الثأر رغم عدم وجود

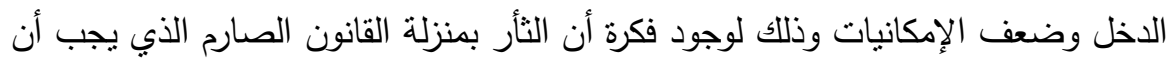
يقبله المجتمع بخلاف دور العصبيات في جرائم الثأر .

\section{أهم النتائج القيزيقية المرتبطة بجريمة الأخذ بالثأر : بأن}

ا ـ بالنسبة لمتغير الموطن الأصلي (ريف - حضر): تنين للباحث من خلال دراسة الحالة أن

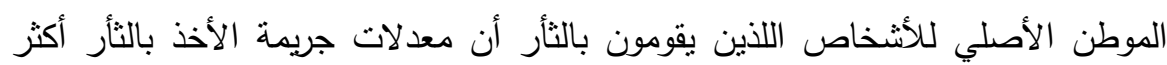

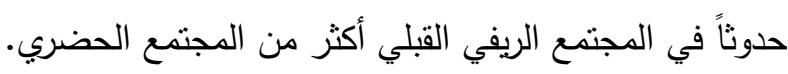
r. بالنسبة لمتغير مكان العمل: تبين للباحث أن الذين يعملون في السياحة بسبب الاتبع الاتصال

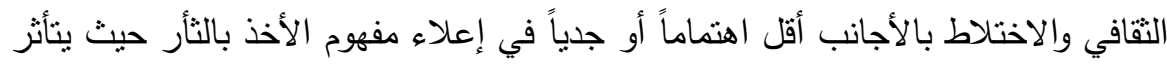

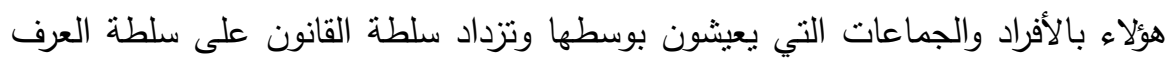
مما أثر على تغيير الفكر والرأي حول موضوع الثأر سواء من الإنسان أو حتى فئى في الممتلكات (الزراعية - الحيوانية - التجارية).

r. بالنسبة لمتغير التكنولوجيا المتاحة: يرى الباحث بعد تحليل ونتخيص الحالات أن الن

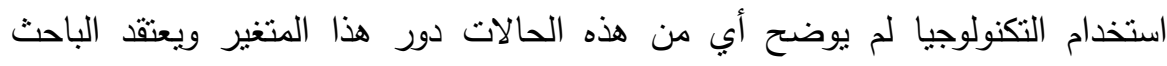
الحالي أن تفسير ذلك يرجع إلى ضعف الجانب الاقتصادي المتاح لتوفير هذه التكنولوجيا في الاستخدام في الثأر إلا أنه بتعمق الباحث الحالي في قراءات الأحداث التي مرت في لهي الفترة الماضية خلال العشر سنوات أن هناك جرائم ثأر تتم عن طريق هذه التئ التكنولوجيا فهناك من يقوم بسببه فكرة الثأر مثل من يأخذ صورة إحدى الفتيات من وسائل الاتصال ويقوم بالتعريض لها ومن هنا قد ينشأ شجار ينتج عنه القتل ومن ثم تنشأ جرائم الثأر خلاف عما استطاع فيه الإرهابيون من إتمام بعض الجرائم وغيرها باستخدام هذه الوسائل 
التكنولوجية ومن ثم من المحتمل أن يستخدم الثباب الجديد منل هذه التكنولوجيا في

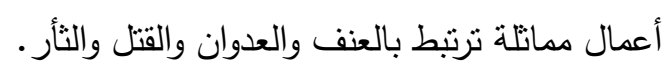

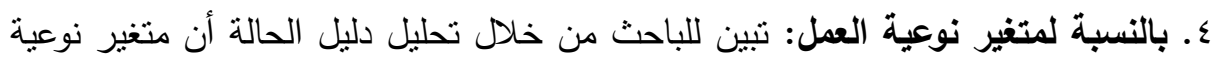

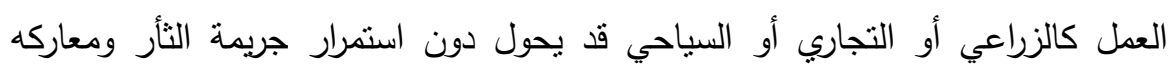
الدامية فقد تبين للباحث أن العمل في المجال السياحي قد يحد من انتشار جريمة الأخذ

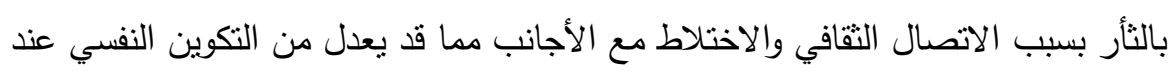
الفرد للاتجاه السالب نسبياً نحو الثأر وذللك في ضوء أبعاد العاد العادات والتقاليد والبعد الديني

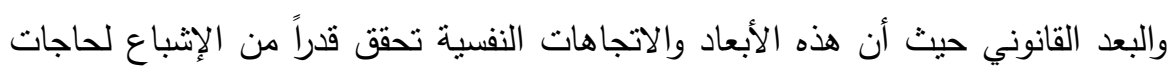

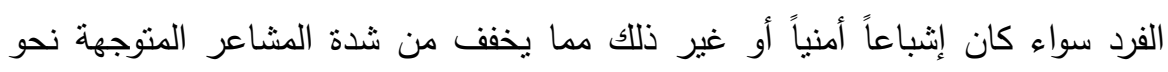

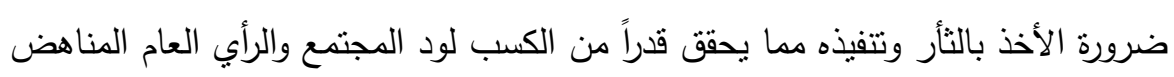
للثأر • والعكس من ذلك أن الذين يعملون في الزراعة فهم أكثر تمسكاً بفكرة الثأر ويقل

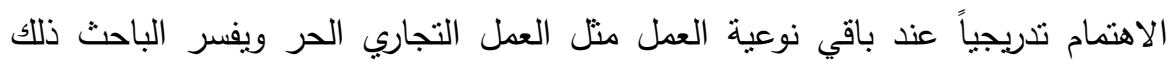
بسبب الاختلاط بثقافات أخرى كذلك ارتفاع مستوى المعيشة وقلت وقت نداف الفراغ عكس

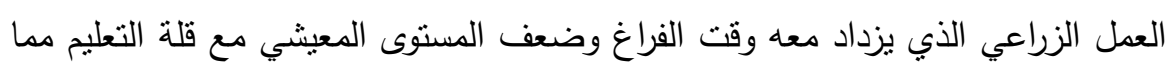
يزيد من الخضوع لتقاليد الثأر خضوعاً لا عقل لله ولا منطق.

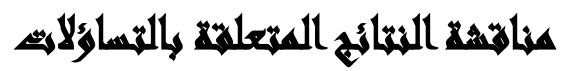

مناقثة النتائج المتعلقة بالتساؤل الأول هل هناك علاقة بين بعض متغيرات البيئة الاجتماعية (السن - المؤهل - النوع - الاخل - المكانة الاجتماعية - ترتيب الأبناء)

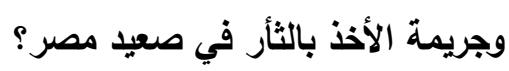

يتضح لنا من النساؤل السابق وبعد قيام الباحث بتحليل وتنشخيص الحالات التي نم

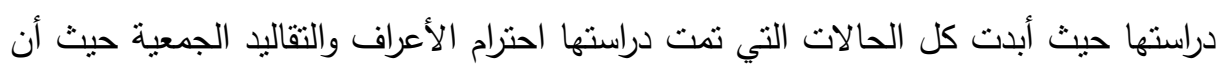

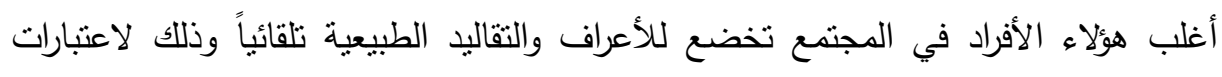

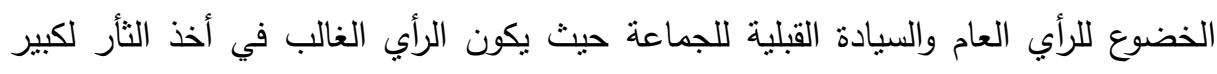

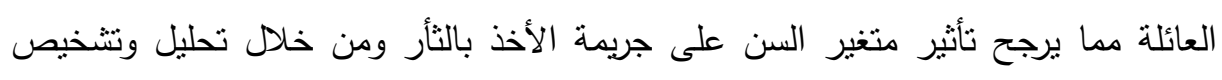

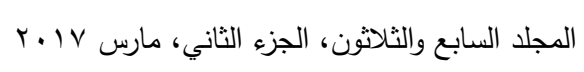


دليل دراسة الحالة أن هناك علاقة بين متغير الاخل وجريمة الأخذ بالثأر حيث أن الأغنياء

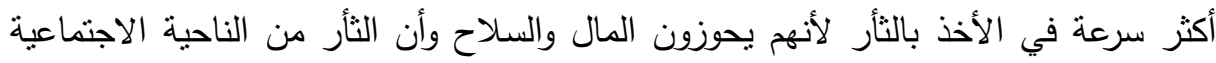

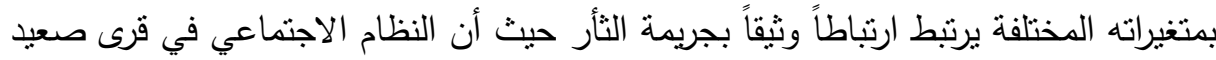

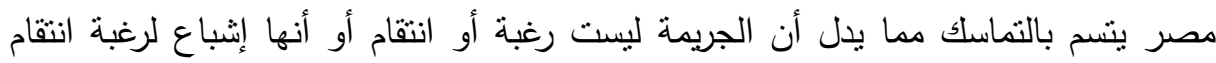
دون الأخذ في الاعتبار الملامح الأساسية والقوانين الخاصة التي تحكم هذه النظم الاجتماعية

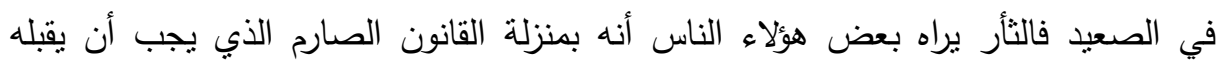

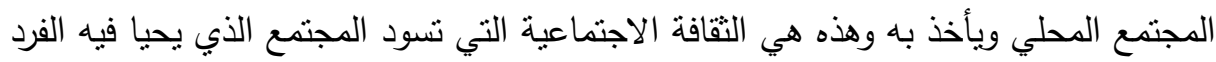

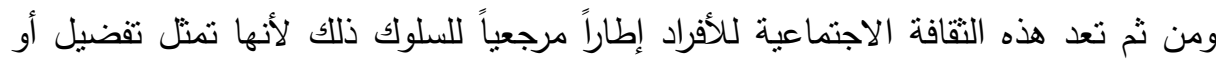

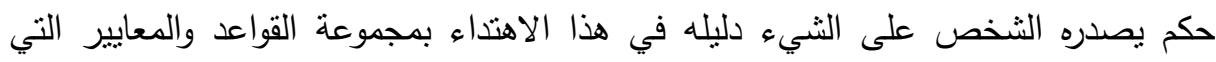
تسود ثقافة مجتمعه وبالتعمق في تحليل الحالات تبين أنه رغم وجود متغير الاخل عند العند العائلة

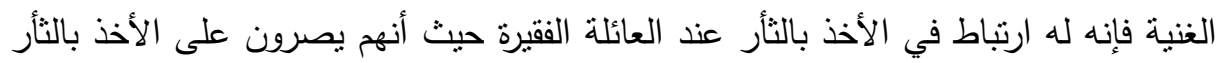

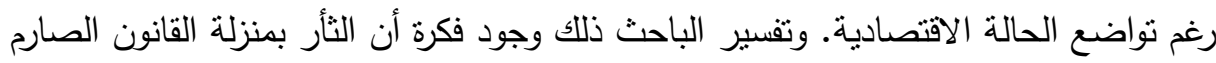
الذي يجب أن يقبله المجتمع بالإضافة إلى دور العصبيات في علاقتها بجريمة الأخذ بالثأر.

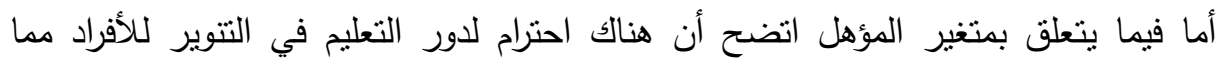

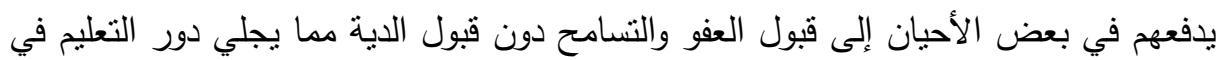

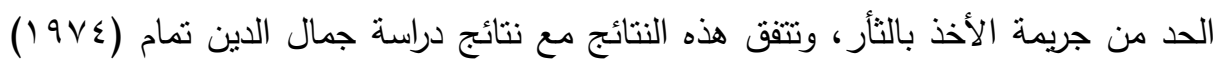

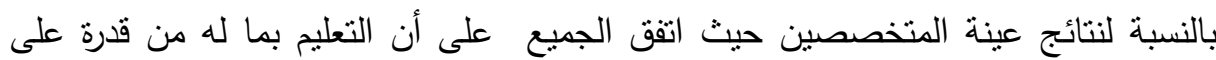

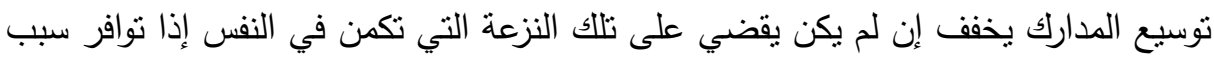

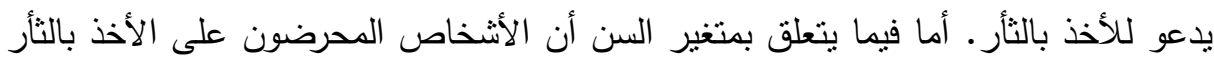

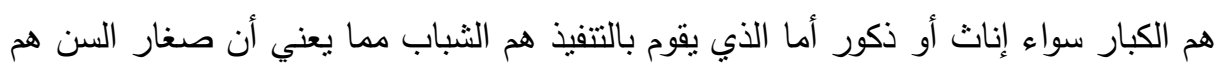

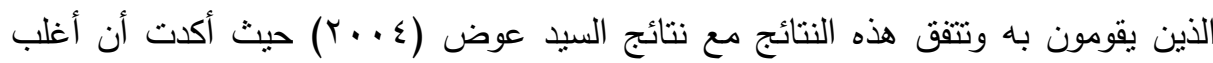

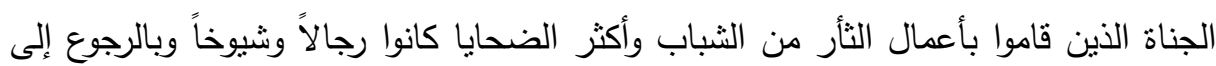

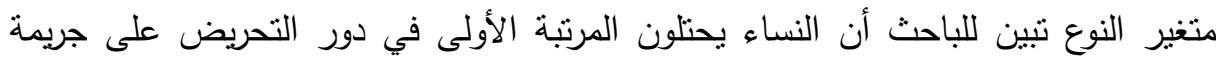
الأخذ بالثأر حيث أبدى ^ حالات من مجموع ·r حالة من عينة البحث أن السيدات الكبار 


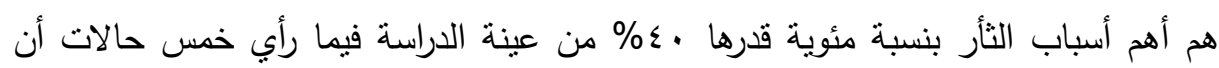

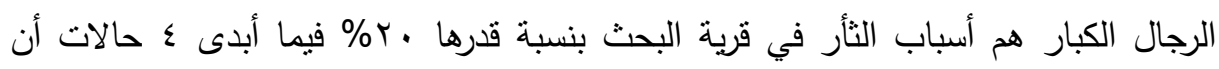

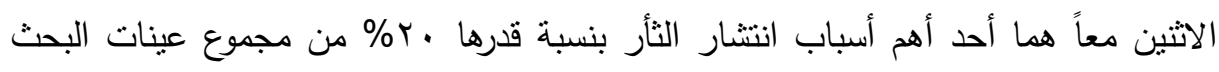

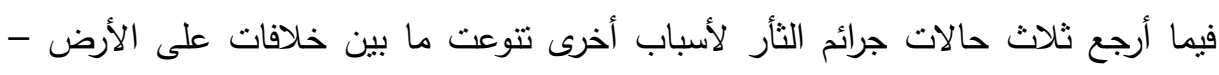

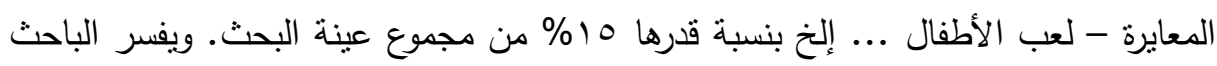

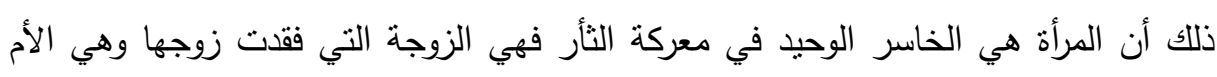

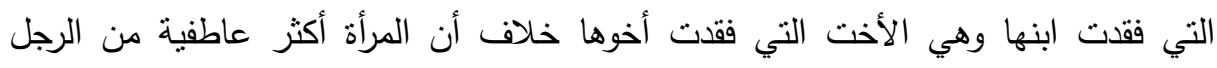

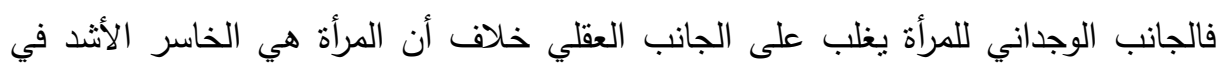

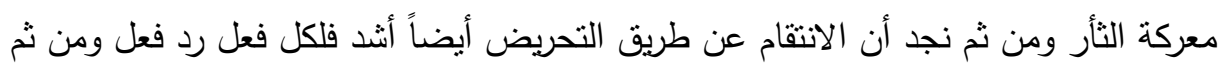

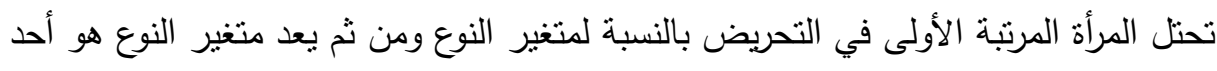

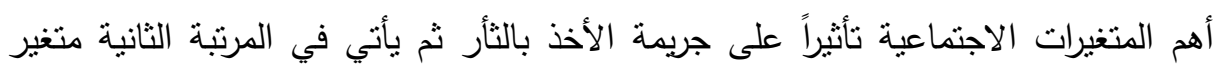

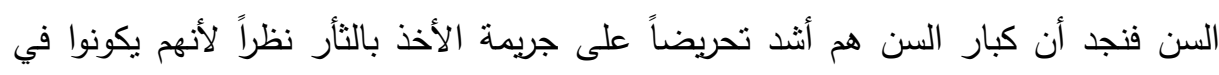

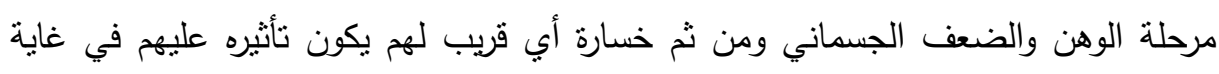

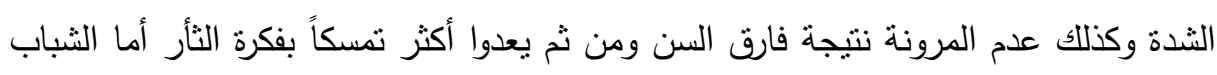

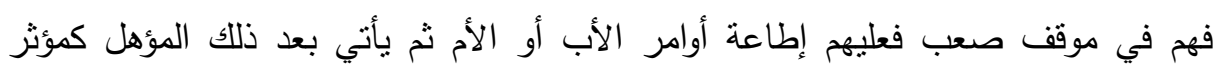

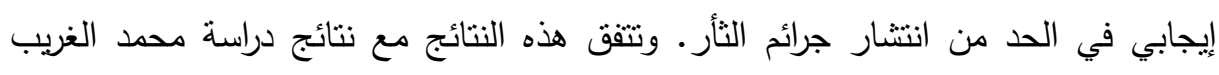

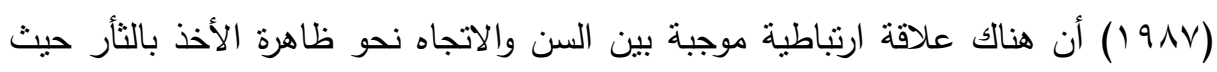

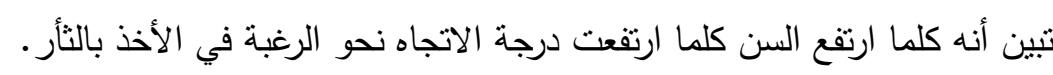

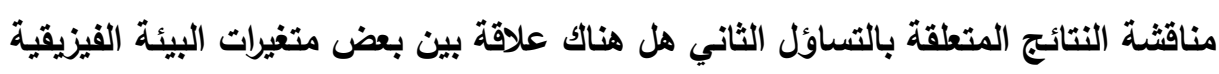

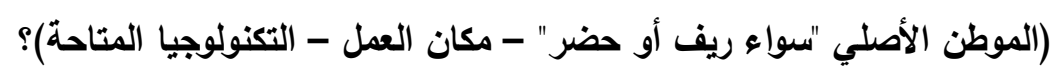

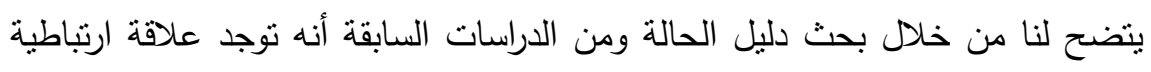

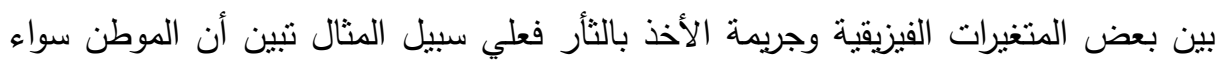

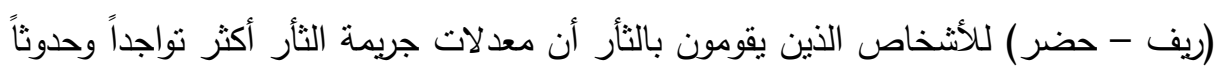

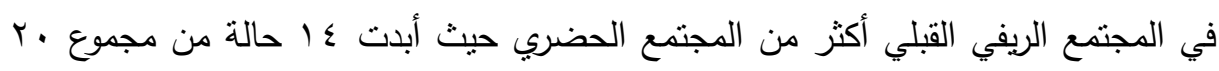

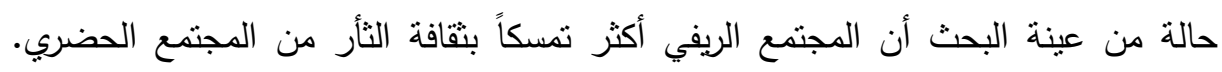

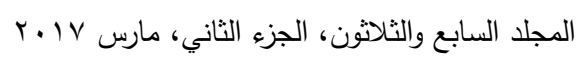


ويفسر الباحث ذلك أن حجم الثأر يزداد في هذه المجتمعات المتجانسة والمتقاربة اجتماعياً ذات موقع الإقامة المنغلق ذات النظام الاجتماعي المتفق والمرنبط أكثر بالنظام الاجتماعي هندي

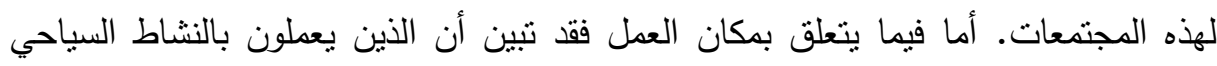
بسبب اتصالهم الثقافي والاختلاط بالأجانب أقل اهتماماً أو جدياً في إعلاء مفهوم الأخذ بالثأر حيث يتأثز هؤلاء الأفراد بالجماعات التي يعيشون في وسطها وتزداد سلطة القانون على سلطة

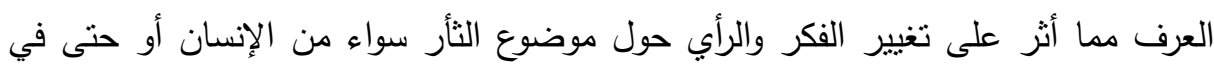
الممتلكات (الزراعية - الحيوانية - التجارية) وقد تبين من تحليل الحالات والدراسات السابقة أن استخدام التكنولوجيا المتاحة لم توضح أب من هذه الحالات دور هذه التكنولوجيا في جريمة

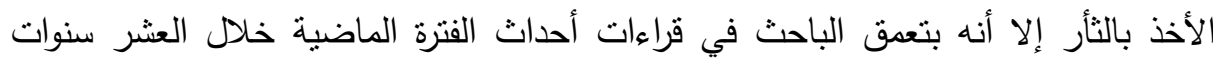
الماضية أن هناك جرائم إرهابية تتم عن طريق هذه التكنولوجيا مما يقوم بسببه جرائم الثأر

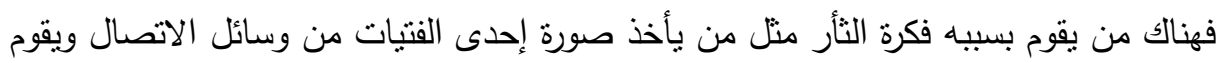

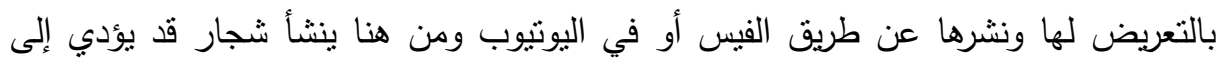

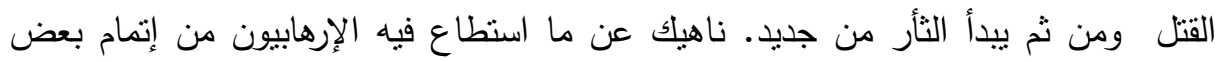

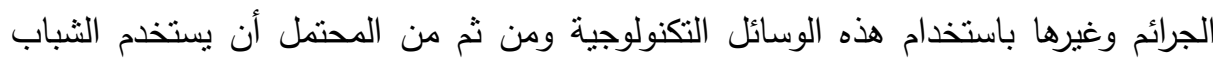

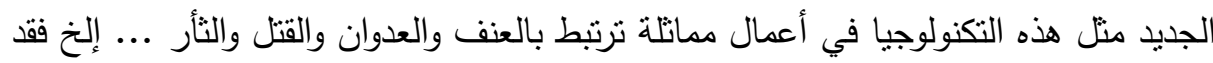
اختلفت طريقة تتفذ الأخذ بالثأر فقد كانت قديماً تتم عن طريق الضرب على على الرأس باستخدام الشوم والعصي أو الذبح أو الطعن عن طريق فأس أو سكين أو ما يسمى في الصعيد فئ (منجل

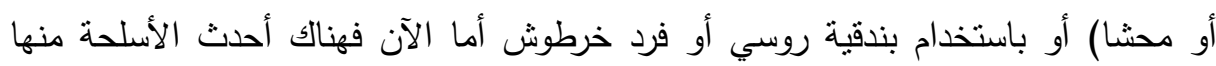

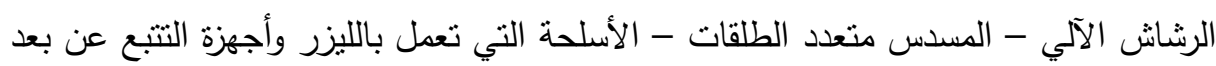
والقنابل اليدوية والقنابل التي تتفجر عن بعد عن طريق الريموت كونترول أو حتى المحمول

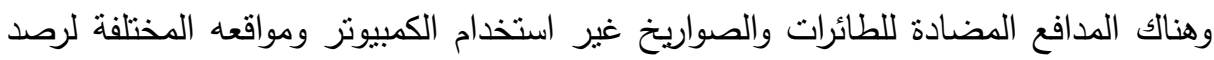
وتحرك الخصوم مثل الفيس بوك والماسنجر والفيير والوتس وغيرها كلها متغيرات حديثة لم تكن موجودة في الصعيد من ذي قبل. ومادام الثباب هم من يقومون بالتتفيذ فالثباب أيضاً

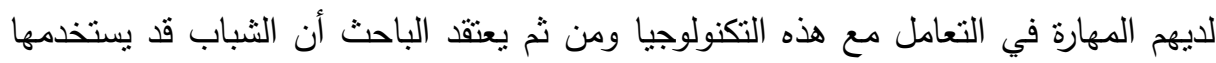


في جرائم الثأر ومن ثم يزداد معها نسبة الضحايا ويزاد معها القتل الجماعي وهو متغير جديد

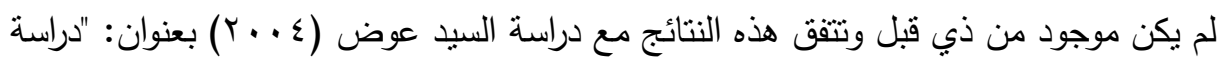

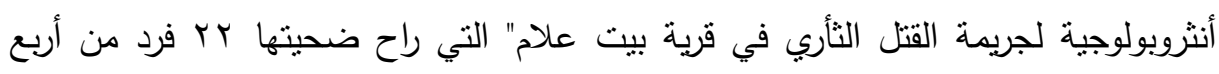
عائلات حيث كثفت النتائج أن أغلب الجناة من الثباب وأكثر الضحايا كانوا رجالاً وشيوخاً وأطفالاً أي مختلف الفئات العمرية ويفسر الباحث الحالي ذلك بسبب الستخدام التكنولوجيا

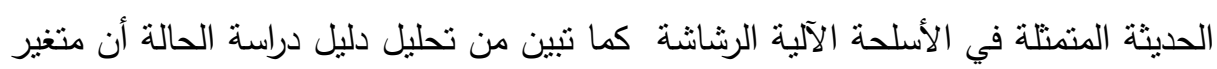

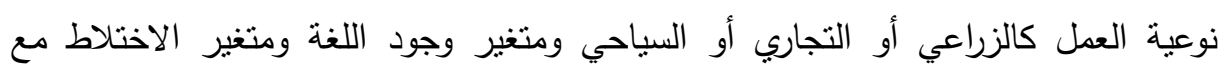
الأجانب وموقع إقامة الأفراد ووجود خبرات السفر للخارج نرتبط بالثأر حيث إجادة اللغة والعمل

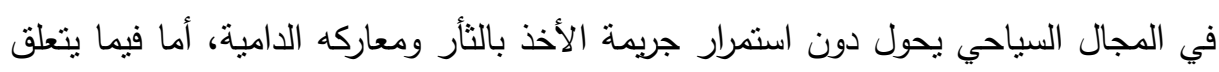

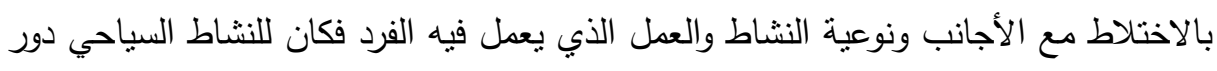
كبير في الاتجاه نحو الأخذ بالثأر حيث أن المستويات التعليمية في ظل وجود اللغة والاختلاط

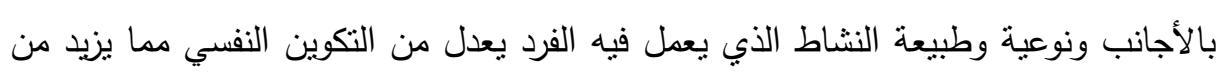

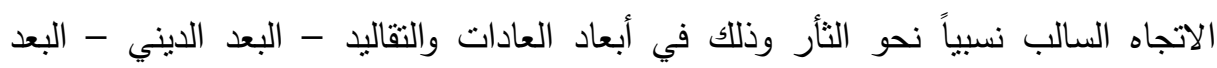

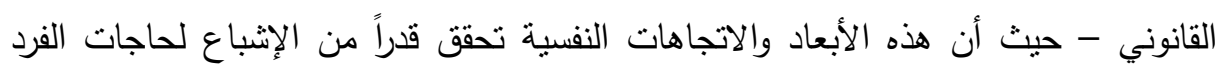

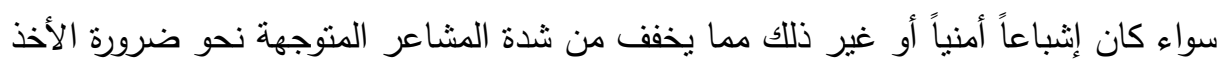

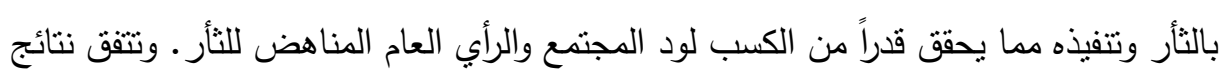

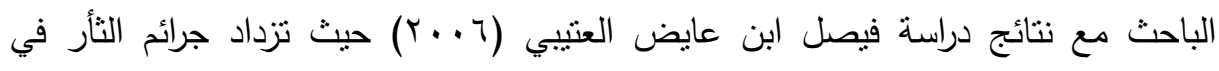
المناطق الريفية والقرى عنها في المدن حيث تكون الحدود الزراعية متلاصقة فتكون بؤرة الاصطدام.

\section{تروسيامت التوراسة}

1-تشكيل محاكم خاصة سريعة للفصل في قضايا الثأر على أن تتشكل هذه المحاكم من قضاه عرفيين مهنهم تقارب وجهات النظر بين القبائل المتصارعة والسعي للصلح بين

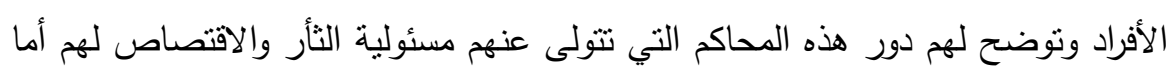
القضاة الرسميين فوظيفتهم تطبيق القانون لكن في ثوب العرف والثون والعادات والتقاليد لأبناء

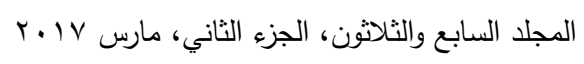


الصعيد حتى يتقبل أبناء الصعيد هذه الأحكام ويعطي لجميع القضاة صفة الرسمية والإلزام لهذه القرارات حتى يتم الصلح.

r-العمل على انتشار التعليم في جميع قرى الصعيد والاهتمام بالتعليم العالي حيث أن

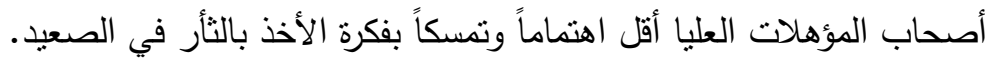
ب-الاهتمام بخطط التتمية الثاملة في جميع صعيد مصر .

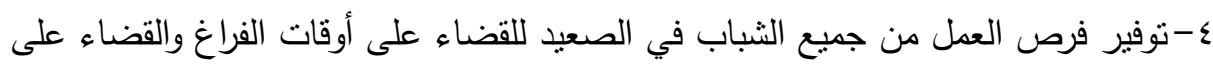
الفقر والبطالة. ه- الاهتمام بالمرأة في الصعيد من خلال عمل برامج توعية لها والاهتمام بتعليم وعمل المرأة

$$
\text { فهي تعد نصف المجتمع المؤثر في صعيد مصر . }
$$

צ-الاهتمام بالمجالس العرفية وتكون تحت رعاية المحافظ أو الدولة وتتبنى الدحافظة رسمياً

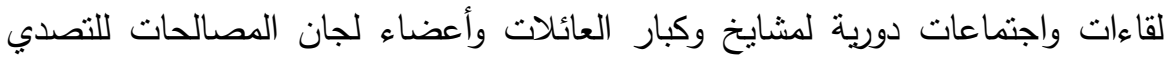

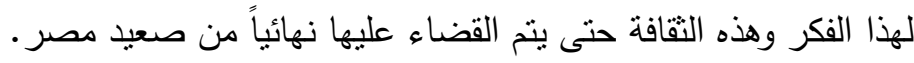

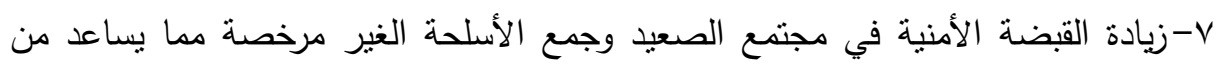

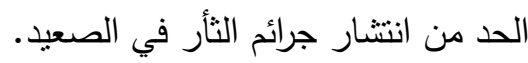

\section{المرالئ2}

السيد رمضان(910): الجريمة والانحراف من المنظور الاجتماعي، القاهرة، المكتب

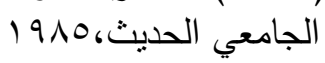

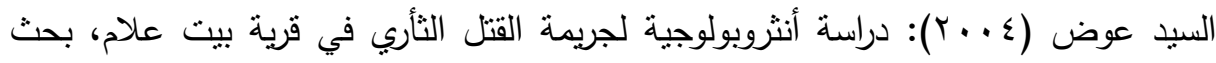

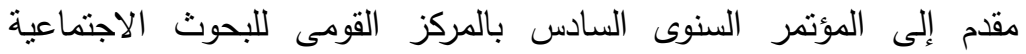

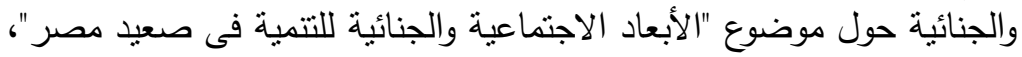
كلية الآداب بقنا، جامعة جنوب مورع الوابعاد الاجنياع السيد علي شتا (919v ()): علم الاجتماعي الجنائي، الاسكندرية، دار المعرفة السيد الحسيني(اله (م): المدينة، دراسة في علم الاجتماع الحضري، طس، القاهرة، دار

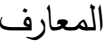


أحمد رأفت عبد الجواد(ب 9 ( )): مبادئ علم الاجتماع، القاهرة، مكتبة نهضة الثرق

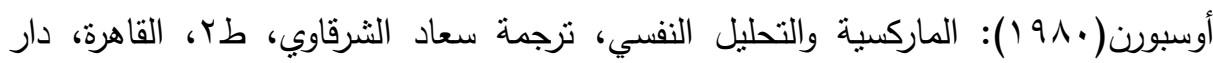
المعارف الماركسن

أحمد عوض بلال(910 (1): علم الإجرام، القاهرة، دار التقافة العربية

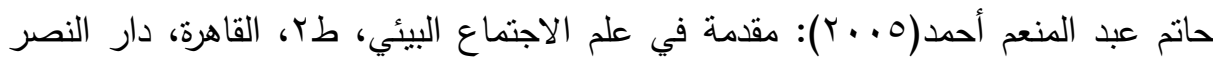
للتوزيع والنشر

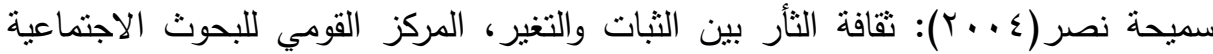

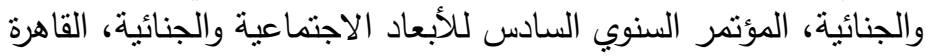

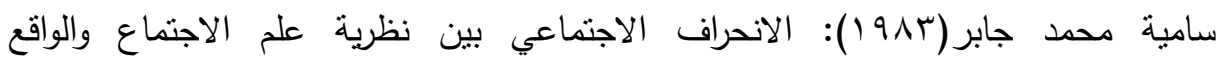
الاجتماعي، الإسكندرية، دار المعرفة الجامعية

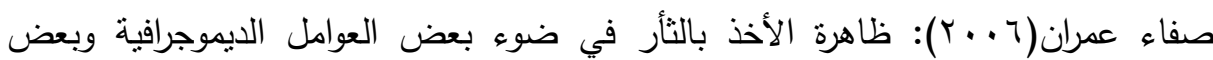
سمات الثخصية، دراسة نفسية في محافظة أسيوط، رسالة ماجستير ، كلية الأنية

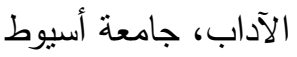

صلاح عبد المتعال(·191 (): التغير الاجتماعي والجريمة، القاهرة، مكتبة وهبة

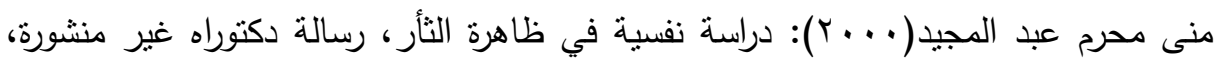

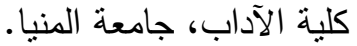

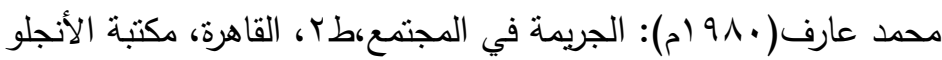
هدى عبد الفتاح الألفي(9Av (م)): نماذج السلوك الانحرافي في المناطق المتخلفة، دبلوم معهد العلوم الاجتماعية، كلية الآداب، جامعة الإسكندرية.

Fred, W. Riggs (1961): "The Ecology of Administration", London: Asia Publishing House.

John Lewis and Others (1969): "Social Problems", Fourth Edition, Bombay: The Time of India Press.

Poussaint, Alvin F(1984): Paper presented at the Annua convention of the American psychological, Association, August.

Wenberg N (1994): Death Studies, Journal of psychology, vol 186.

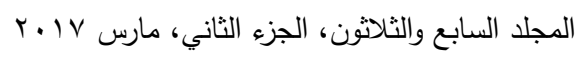


مجلة العلوم البيئية

معهد الدراسات والبحوث البيئية - جامعة عين شمس لمس لمس

\title{
THE SOCIAL AND PHYSICAL VARIABLES ASSOCIATED WITH TAKING VENGEANCE CRIME A CASE STUDY ON A VILLAGE IN UPPER EGYPT
}

\author{
Hany, A. F. ${ }^{(1)}$; Ahmed, H. A. ${ }^{(1)}$ and Hasanin, A. E. \\ 1) Institute of Environmental Studies and Research Ain-Shams \\ University
}

\begin{abstract}
Vengeance crime considers one of the most dangerous social crimes in human societies. It is an old crime since man ever has existed on earth. It is the first enemy threatening societies and nations' stability, safety, development and progress. This study objective is to identify the relationship between social and physical variables and crime of taking revenge. In order to study this issue, the researcher has designed an interview guideline for collecting data, examining, and diagnosing the study cases $(n=20)$ items. The form includes some demographic data including (age-sex-qualification-social status-career-number of children-residency place-average income-agrarian property size) in addition to data concerning the family of researched items, using technology, cultural communication, reasons for vengeance crimes and data of resolving problem. The researcher uses the qualitative-analytical method and the case study method. The study results indicate that there are some social variables (age - certificate - social status-dependencyincome - order of children - family position - degree of kinship) connect to taking revenge crime, as all examined cases show respect to norms, traditions, and societal customs as a natural submission to public opinion and tribal Sovereignty of the group. The study results indicate that there are some (physical variables) associate with taking revenge crime such as (original residence - work location - cultural communication - available technology - residency locate - perfection of language - quality of work - communicating with foreigners 118

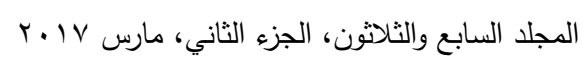


experiences of travelling abroad). And crime of taking revenge in Upper Egypt.

The study recommends the necessity for setting the Upper Egypt on the plan list of development, establishing as well separate juridical panels that would be responsible for taking vengeance causes in Upper Egypt and consist of customary and formal judges. 